\title{
SESGOS Y PAUTAS DEL COMPORTAMIENTO EMPRESARIAL Y TEMPORALIDAD ILÍCITA ${ }^{1}$
}

\author{
Ignasi Beltran de Heredia Ruiz \\ Profesor Agregado y TU Acreditado \\ Universitat Oberta de Catalunya (UOC)
}

\begin{abstract}
El objeto de este ensayo es tratar de averiguar, en un plano introspectivo, los motivos que impulsan a los empresarios a no respetar las normas que disciplinan la contratación temporal causal. La cronificación de la temporalidad ilícita (o la sistemática ineficacia de las normas que han tratado de corregirla), evidencia la necesidad de identificar los factores que expliquen este comportamiento empresarial. A partir del enfoque de lo que se conoce como "análisis económico del derecho del comportamiento" (behavioral law and economics) y los avances de la psicología y la neurociencia, el estudio hace un análisis de los sesgos y limitaciones cognitivas que inciden en la toma de decisiones empresariales a la hora de elegir la modalidad de contratación en la incorporación de nuevos trabajadores. En concreto, partiendo de lo que se conoce como la "teoría de las perspectivas", propuestas por los psicólogos KAHNEMAN y TVERSKY, el propósito de este estudio es tratar de descifrar las pautas del comportamiento humano en este contexto. En la medida que, como se expondrá, este enfoque facilita la compensación de los impulsos que determinan estas decisiones empresariales, este trabajo propone, a modo de lege ferenda, formulaciones normativas alternativas que, en hipótesis, podrían contribuir a reducir el uso de la contratación temporal ilícita y, así, migitar la acentuada segmentación de nuestro mercado de trabajo.
\end{abstract}

The purpose of this essay is to find out, on an introspective level, the causes that drive employers to not respect the norms that rule temporary causal hiring. The chronification of illegal temporality evidences the need to identify the factors that explain this behavior. From behavioral law and economics approach, the study makes an analysis of the biases and cognitive limitations that affect employers' decisions in this field. This paper proposes, as a lege ferenda, alternative normative formulations that, in hypothesis, could help to reduce illegal temporary contracts.

IUSLabor 3/2019, ISSN 1699-2938, p. 114-151

DOI. 10.31009/IUSLabor.2019.103.05

\footnotetext{
${ }^{1}$ Este trabajo ha sido calificado como Finalista en la edición 2019 del Premio Estudios Financieros del CEF en la modalidad de Derecho del Trabajo y de la Seguridad Social.
} 
Fecha envío: 9.10.2019 | Fecha aceptación: 15.11.2019

Title: Biases and employer's behavior patterns and illegal temporary contracts

Palabras clave: contratación temporal ilegal, sesgos, teoría de las perspectivas

Keywords: biases, illegal temporary contract, prospect theory

\section{Sumario}

1. Las limitaciones del Derecho y de la Economía y el potencial explicativo de la Psicología de las Elecciones

2. Sesgos y pautas del comportamiento empresarial e incidencia en las decisiones sobre las modalidades de contratación

2.1. El punto de partida: extinción contractual y costes de gestión

2.2. La aversión a las pérdidas (y el efecto dotación)

2.3. Justicia y Esfuerzo

2.4. El dolor de pagar

2.5. Problemas de autocontrol

2.6. Optimismo no realista (y la adaptación hedónica)

2.7. Disponibilidad

2.8. Conformidad

2.9. Ansarinos, impronta, anclas e inercias

3. Valoración final

4. Bibliografía 


\section{Las limitaciones del Derecho y de la Economía y el potencial explicativo de la Psicología de las Elecciones}

La acusada y patológica segmentación de nuestro mercado de trabajo es un fenómeno ampliamente conocido. No obstante, las sucesivas medidas legislativas dirigidas a potenciar la contratación indefinida han tenido una escasa eficacia, derivando en un uso de la contratación temporal ilícita crónico.

Partiendo de esta realidad, permítanme que empiece la exposición de este ensayo formulándoles dos preguntas:

\section{¿Por qué los empresarios no cumplen con las causas de temporalidad legalmente descritas? \\ Si supiéramos qué impulsos determinan el comportamiento empresarial, ¿podríamos configurar normativamente una arquitectura de las decisiones que permitiera reducir la temporalidad ilícita?}

El Derecho es uno de los principales prescriptores del comportamiento social. Las normas jurídicas, a partir de una compleja estructura institucional, aspiran a dirigir la conducta de los ciudadanos, tratando de motivar o promover las acciones preferidas y de disuadir las indeseadas.

Sin embargo, la ciencia jurídica ha pecado de autosuficiente, pues, la obediencia no está garantizada por el mero hecho de la promulgación de una norma. Los destinatarios no reaccionan conforme a una racionalidad paramétrica (obviando las preferencias de los demás), sino que lo hacen estratégicamente (esto es, teniendo en cuenta las elecciones de quienes les rodean y sus conductas esperadas $)^{2}$.

El dogmatismo jurídico ha estado centrado en los problemas del sistema legal desde la perspectiva de la dialéctica entre justicia y seguridad jurídica y carece de medios para evaluar la reacción estratégica de los ciudadanos ante la norma. En consecuencia, no puede saber anticipadamente si las normas van a alcanzar el objetivo que persiguen y/o en qué medida. Tampoco puede evaluar si los recursos invertidos para conseguir estos fines son razonables en términos del éxito obtenido. En definitiva, es incapaz de obtener una respuesta a las preguntas que les formulaba anteriormente, especialmente, porque

\footnotetext{
${ }^{2}$ CALSAMIGLIA (1988), p. 307, 308, 313 y 329. Vid. también, PASTOR PRIETO (1984), p. 155 a 157. No cabe duda que hay situaciones en las que la norma puede inducir a no respetarla, en la medida que, aunque ese comportamiento vaya asociado a una eventual sanción, la utilidad que se obtenga sea mayor que si se sigue.
} 
no tiene instrumentos que le permitan identificar el comportamiento previsible de los ciudadanos ante la norma.

Así pues, si aspiramos a resolver esta cuestión (o cuanto menos, a enfocarla adecuadamente), no tenemos más remedio que acudir a otras ciencias y enfoques metodológicos.

El Análisis Económico del Derecho (o Law \& Economics), se ha erigido en una poderosa herramienta para tratar de identificar un patrón de conducta que explique el comportamiento estratégico del individuo ante la norma. Y, por consiguiente, atesora (en hipótesis) una potente capacidad predictiva.

Sin embargo, desde postulados "conductistas" se ha puesto en duda la validez de la teoría de la elección racional del homo oeconomicus, evidenciando sus limitaciones intrínsecas (además de las morales asociadas al utilitarismo ${ }^{3}$ ). Como expone ARIELY (2008, p. 258), "la economía estándar presupone que somos racionales; que conocemos toda la información pertinente relacionada con nuestras decisiones, que podemos calcular el valor de las distintas opciones que afrontamos, y que cognitivamente nada nos impide sopesar las ramificaciones de cualquier potencial decisión. El resultado es que se da por supuesto que tomamos decisiones lógicas y sensatas. Y aunque de vez en cuando tomemos una decisión equivocada, la perspectiva de la economía estándar sugiere que de inmediato aprenderemos de nuestros errores, bien por nosotros mismos, bien con la ayuda de las "fuerzas del mercado"".

Y es obvio que esto no es así. Siguiendo la exposición de $\operatorname{THALER}^{5}$ (2016, p. 29 a 32), el problema de la teoría económica reside en que emplea un modelo en el que se "sustituye al Homo sapiens [y que denomina "Humanos"] por una criatura ficticia llamada Homo economicus" (y que, para abreviar, suele llamar como "Econ") y esto provoca que con los modelos económicos se alcancen predicciones erróneas ${ }^{6}$. Añadiendo que "irónicamente, la existencia de modelos formales basados en esta idea equivocada del comportamiento humano es precisamente lo que concede a la ciencia

\footnotetext{
${ }^{3}$ Extensamente sobre cómo los mercados a través de los incentivos desplazan la moral, SANDEL (2013), p. 89 y ss.

${ }^{4}$ Siguiendo con ARIELY (2008, p. 259 y 260), “según los supuestos de la economía estándar, todas las decisiones humanas son racionales e informadas, motivadas por un concepto preciso de la valía de todos los bienes y servicios, y de la cantidad de felicidad (utilidad) que probablemente producirá cada decisión. Bajo esta serie de supuestos, todos los participantes en el mercado tratan maximizar su beneficio y se esfuerzan en optimizar sus experiencias".

${ }^{5}$ Premio Nobel de Economía 2017.

${ }^{6}$ TIROLE (2018, p. 137) - Premio Nobel de Economía 2014 - también se refiere al homo economicus como una "ficción".
} 
económica su reputación de ser la más poderosa de las ciencias sociales, poderosa en dos sentidos claramente diferenciados. El primero es indiscutible: de entre todos los conflictos sociales, los economistas son los que más influencia tienen en las políticas públicas (...). El otro es que la economía también está considerada como la más poderosa de las ciencias sociales en el ámbito intelectual, poder que se deriva del hecho de que posee un núcleo teórico unificado del que parte casi todo". Hasta el extremo de que "los economistas suelen comparar su campo con el de la física, ya que al igual que ésta, la economía se basa en unas pocas premisas iniciales"7.

El problema - siguiendo con el mismo autor - es que "premisas en las que se basa la teoría económica son imperfectas", porque, primero, "los problemas de optimización a los que se enfrenta la gente normal ["humanos"] a menudo son demasiado difíciles como para que los puedan resolver, o incluso acercarse a su resolución"; segundo, "las creencias a partir de las cuales la gente toma sus decisiones no son imparciales. Puede que el exceso de confianza no aparezca en el diccionario de los economistas, pero es un rasgo muy arraigado en la naturaleza humana, y existen innumerables otros sesgos bien documentados por los psicólogos",; y, tercero, "existen numerosos factores que el modelo de optimización no incluye". De hecho, añade que, lejos de ser propiedades Humanas ilimitadas, en realidad operan las siguientes restricciones: "racionalidad limitada, fuerza de voluntad limitada y egoísmo limitado"?.

\footnotetext{
${ }^{7}$ En otro momento del mismo trabajo (p. 93) afirma que "No existe ninguna forma lógica de llegar a la conclusión de que los mercados transforman a las personas en agentes racionales".

${ }^{8}$ Muchas de las actividades económicas, apuntan AKERLOF y SHILLER (2009, p. 10), lejos de tener motivaciones racionales, están gobernadas por "espíritus animales" (animal spirits), ya que los "estímulos que mueven a las personas no siempre son económicos ni su comportamiento es racional cuando persiguen este tipo de intereses". Y la "confianza" (p. 32 y ss.), que implica que "una conducta sobrepasa un acercamiento racional en la toma de decisiones", y su impacto en las fases recesivas de la economía (especialmente cuando se disipa) es particularmente ilustrativa de esta aproximación. En términos similares, TIROLE (2018, p. 153) afirma que "en el corazón de la vida económica y social está la confianza". Y HARARI (2015, p. 203) se refiere al dinero como "el más universal y eficiente sistema de confianza mutua que jamás se haya inventado".

${ }^{9}$ THALER (2016), p. 362; y SUNSTEIN, JOLLS y THALER (1998), p. 1476. Limitaciones que también son apuntadas por CALABRESI (1984, p. 107), cuando afirma que las personas desconocen aquello que más les conviene. Una muestra también en CONTHE (2007), p. 31. Más al detalle, siguiendo de nuevo a SUNSTEIN, JOLLS y THALER (1998, p. 1477 y 1479), "bounded rationality, an idea first introduced by Herbert Simon, refers to the obvious fact that human cognitive abilities are not infinite. We have limited computational skills and seriously flawed memories". A su vez, en relación a la voluntad limitada, "This term refers to the fact that human beings often take actions that they know to be in conflict with their own long-term interests". Y, finlamente, "we use the term bounded self-interest to refer to an important fact about the utility function of most people: They care, or act as if they care, about others, even strangers, in some circumstances (...) the agents in a behavioral economic model are both nicer and (when they are not treated fairly) more spiteful than the agents postulated by neoclassical theory".
} 
Estas limitaciones cognitivas del ser humano ${ }^{10}$ (o "racionalidad limitada" - según H. $\mathrm{SIMON}^{11}$ ) precipitan errores en la interpretación de los hechos, en la toma de decisiones y sesgan la identificación de lo que más le conviene (traduciéndose todas ellas en actuaciones que van en contra del propio interés de los individuos o evidencian el carácter inconsistente de sus preferencias). De modo que (ARIELY, 2008, p. 252, p. 262 y 263), "no somos nobles en nuestra razón ni infinitos en capacidad, y nuestra comprensión resulta ser más bien pobre". Especialmente porque hay una serie de fuerzas (emociones, relatividad, normas sociales, etc.) que influyen en nuestro comportamiento y (con independencia de si somos expertos o novatos) las subestimamos, provocando errores sistemáticos y previsibles. Somos víctimas de las "ilusiones decisorias" de nuestra mente (de un modo similar a lo que nos sucede con las ilusiones ópticas), pues, nuestras decisiones parten de la representación de la realidad que nuestro cerebro ha construido a partir de nuestros limitados sentidos que la naturaleza nos ha proporcionado ${ }^{12}$. No sólo no somos racionales todo el tiempo, sino que, incluso, podemos acabar tomando decisiones que nos perjudican (TIROLE, 2018, p. 138 y 139$)^{13}$.

En definitiva, en la medida que nuestro sistema cognitivo y el juicio que de él se deriva está sesgado, hay elementos suficientes para poner en duda el fundamento medular de la teoría económica más ortodoxa, esto es, la teoría de la elección racional y, por ende, de la maximización de la utilidad esperada.

Ahora bien, la existencia de estas limitaciones, no "significa que el comportamiento de la gente es impredecible, sistemáticamente irracional, aleatorio, libre de reglas, o ajeno a los cientificos sociales" ${ }^{14}$. En efecto, diversas experimentaciones han evidenciado que (ARIELY, 2008, p. 259 y 260) los Humanos somos previsiblemente irracionales ${ }^{15}$. En

\footnotetext{
${ }^{10}$ Se sigue al respecto la exposición que al respecto llevan a cabo CABRILLO RODRÍGUEZ y ALBERT LÓPEZ-IBOR (2011), p. 209 a 212.

${ }^{11}$ Premio Nobel de Economía de 1978.

${ }^{12}$ Al respecto también, SUNSTEIN (2017), p. 10 y ss. Y especialmente cuando afirma (p. 12): “los descubrimientos sobre el comportamiento humano crean problemas para el argumento epistémico porque muestran que la gente comete muchos errores, algunos de los cuales pueden resultar extremadamente dañinos". Si bien es cierto que (p. 13 y 14) "la mayor parte del tiempo, los mercados libres son la mejor salvaguarda contra los errores cognitivos", no puede olvidarse que "los mercados libres también pueden recompensar a los vendedores que explotan los errores humanos".

${ }^{13}$ Valoración que también se ha constatado desde el punto de vista de la psicología social. En este sentido, OVEJERO BERNAL (2015, p. 60), afirma que "somos tan poco racionales que ni siquiera somos conscientes de nuestra irracionalidad, a pesar de la formidable frecuencia con que actuamos irracionalmente". Añadiendo que lo que nos distingue de los demás animales es el lenguaje, la capacidad de cooperación y la irracionalidad: "somos la especie más irracional".

${ }^{14}$ SUNSTEIN $(2012,2)$, p. 54.

${ }^{15}$ O, como exponen SUNSTEIN y THALER (2009, p. 35), "nos equivocamos sistemáticamente".
} 
efecto "nuestros comportamientos irracionales no son ni aleatorios ni insensatos; lejos de ello, son sistemáticos y previsibles. Todos cometemos los mismos tipos de errores una y otra vez, debido a la estructura básica de nuestro cerebro". Porque, como exponen SUNSTEIN y THALER (2009, p. 34 y 34) nuestros sesgos son predecibles porque el conocimiento de nuestro sistema cognitivo ha posibilitado averiguar cómo inciden en nuestra forma de pensar.

Así pues, la economía tiene dificultades para seguir calificándose como "la física social" ". Y esta circunstancia (TIROLE, 2018, p. 137 y 138) la ha forzado a mirar cada vez más al resto de ciencias sociales incorporando sus aportaciones, abandonando su pretensión imperialista (y en base a la cual fagocitaba a sus "hermanas").

Es en este contexto en el que, entre otras disciplinas sociales, debe prestarse una atención muy especial al trabajo de la psicología y la neurociencia. Y, en particular, a los descubrimientos de los psicólogos KAHNEMAN ${ }^{17}$ y TVERSKY, sobre el funcionamiento del cerebro humano. Según estas investigaciones (siguiendo con la exposición de SUNSTEIN y THALER, 2009, p. 35 a 39), pueden distinguirse dos tipos de pensamiento: uno intuitivo y automático y otro más reflexivo y racional (y que en la literatura de la psicología se les denomina, respectivamente, "Sistema 1" y "Sistema 2"). El primero es rápido, instintivo y visceral - no implica lo que normalmente asociamos con la palabra "pensar" -; y el segundo es más premeditado, autoconsciente y afecta al pensamiento consciente. Para ilustrar, si pudiéramos identificarlos con un personaje de ficción, el primero sería predominante en el comportamiento de Homer Simpson y el segundo, en el del Señor Spock de Star Trek.

Pues bien, en la medida que en nuestro día a día no podemos estar permanentemente analizándolo todo, utilizamos "reglas básicas" (o heurísticos) porque son "rápidas y útiles", pero tienen el inconveniente de que pueden "conducir a sesgos sistemáticos". Y los psicólogos han descubierto que estos "heurísticos y sesgos tienen su origen en la interacción del sistema automático y reflexivo".

Pero, ¿qué es una heurística? En concreto, este término (KAHNEMAN, 2012, p. 133) se refiere a un "procedimiento sencillo que nos ayuda a encontrar respuestas adecuadas, aunque a menudo imperfectas, a preguntas difíciles. La palabra tiene la misma raíz que eureka". Este concepto surge a partir de las investigaciones de KAHNEMAN y TVERSKY sobre cómo la gente puede hacer "juicios de probabilidad sin conocer con precisión lo que es la probabilidad", de modo que tendemos a "simplificar de algún

\footnotetext{
${ }^{16}$ Una crítica mordaz a esta pretensión en TALEB (2011), p. 259.

${ }^{17}$ Premio Nobel de Economía en 2002.
} 
modo esta tarea imposible", concluyendo que, cuando se pide "juzgar probabilidades, la gente realmente juzga algo y cree que ha juzgado sobre probabilidades"18.

En definitiva (THALER, 2016, p. 52 y 53), asumiendo que tenemos "un tiempo y una capacidad cerebral limitados (...) por ello nos servimos de sencillas reglas generales las heurísticas - para facilitar la toma de decisiones". Y esto es lo que lleva a las personas a cometer "errores predecibles""

La cuestión es que estas investigaciones han tenido un destacado impacto en la ciencia económica, pues, la empíricamente contrastada irracionalidad de los seres humanos ha permitido evidenciar la existencia de "fallos conductuales del mercado" 20 , o, incluso, lo que se ha venido a llamar "economía de la manipulación" 21 . Todo ello ha propiciado la aparición de una nueva aproximación científica, la "economía conductual" o behavioral economics (homo psicologicus). Según este enfoque, y a partir de las aportaciones de la psicología de elecciones y (ARIELY, 2008, p. 260) basada en el modo como actúa realmente la gente, en lugar de fundamentarse (como propone la economía estándar) en el modo como debería actuar, aspira a dar una explicación más ajustada de nuestro comportamiento. Especialmente porque los economistas conductuales "creen que la gente es susceptible a una serie de influencias irrelevantes de su entorno inmediato [lo que denominan 'efectos contextuales'], emociones irrelevantes, estrecheces de miras y otras formas de irracionalidad”. Y estos “errores también proporcionan oportunidades

\footnotetext{
${ }^{18}$ SUNSTEIN (2009, p. 57): "La heurística en general funciona mediante un proceso de 'sustitución de atributos', según la cual las presonas responden una pregunta dificil que sustituye a una más fácil'.

${ }^{19} \mathrm{Al}$ respecto también KAHNEMAN (2003), p. 183 y ss.

${ }^{20}$ SUNSTEIN (2017), p. 16. Tales fallos (siguiendo con el mismo autor, p. 16 a 18) son entendidos como "fallos del mercado que complementan la explicación estándar de la economía y que provienen de la propensión humana a errar". Lo que, en aras a corregirlos, legitima lo que denomina la "arquitectura de la elección"; y, con ello, ciertas formas de paternalismo (utilizando "la más leve de las formas de intervención y la que más preserva la elección"). Y, como manifestación del mismo, lleva a promover lo que denomina "empujoncitos" o "nudges" (entendidos como "iniciativas que mantienen la libertad de elección mientras conducen por la vía adecuada las decisiones de la gente - tal y como ella misma lo juzga"). Y, de hecho, estos, a menudo son la mejor respuesta, al menos cuando no existe daño a terceros. Y sobre el "paternalismo", cabe distinguir entre el que se focaliza en los "fines" y el que lo hace en los "medios" (siendo este último el que centra la mayor parte de interés de los economistas conductuales, pues, "su meta es crear una arquitectura de la elección que hiciera más probable que las personas promoverán sus propios fines tal y como ellas mismas los entienden"). Lo que, en el fondo (como expone el autor citado), suscita (entre otras cuestiones) qué motiva o acaba justificando el paternalismo y porqué un tercero puede saber mejor que uno mismo lo que más le conviene. Aspecto que no puede ser abordado en este momento.

${ }^{21}$ Según AKERLOF y SHILLER (2016, p. 246 y ss.), la existencia de decisiones disfuncionales provocadas por nuestros sesgos psicológicos (y también a raíz de lo que, en términos más generales, denominan "historias que las personas se cuentan a si mismas") lleva al mercado a proveer bienes y servicios que lejos de beneficiar a los consumidores les acaban perjudicando.
} 
de mejora". Especialmente porque en la medida que "cometemos errores sistemáticos en nuestras decisiones", pueden articularse "estrategias, herramientas y métodos que nos ayuden a tomar mejores decisiones" y "alcanzar lo que deseamos"22.

Y estas teorías psicológicas del comportamiento económico, a su vez, se han erigido en el fundamento de lo que se conoce como "análisis económico del derecho conductista" (behavioral law and economics) $^{23}$. Y que, en palabras de ULLEN (2015, p. 57), "es uno de los más importantes - si no el más importante - desarrollos académicos de la era moderna" 24 .

En este sentido, el impacto de este enfoque en el sistema legal (en tanto que principal prescriptor del comportamiento deseado - como se ha apuntado) puede ser determinante. Como expone SUNSTEIN (2012, 2, p. 55) - que cita a TVERSKY - debe tenerse en cuenta que "descripciones alternativas del mismo problema de elección llevan a preferencias sistemáticamente diferentes; procedimientos de provocación sistemáticamente diferentes dan lugar a elecciones distintas; y la preferencia entre x e y

${ }^{22}$ ULLEN (2015, p. 46 y 47), analizando el impacto de la economía del comportamiento sobre la ciencia económica y las críticas que ha suscitado entre la doctrina más tradicional, sostiene que "el peso de las anomalías en el interior de la TER [Teoría de la Elección Racional] están aumentando y que un nuevo paradigma está arribando. Habiendo dicho esto, creo que también es posible que podamos descubrir en el futuro que para algunos individuos y bajo ciertas circunstancias la elección racional es una buena teoría descriptiva y predictiva".

${ }^{23}$ Un trabajo icónico en este ámbito SUNSTEIN, JOLLS y THALER (1998). Además (siguiendo con la exposición de CABRILLO y ALBERT, 2011, p. 212), entre otras premisas (sobre las que se hará una exposición más detallada con posterioridad), esta corriente justifica, en términos de eficiencia, una mayor intervención del Estado «paternalista», pues, "la gente puede no realizar las mejores elecciones posibles y su nivel de felicidad aumentaría si el Estado les orienta en este sentido". Entre otros, extensamente al respecto (con altas dosis didácticas) en, THALER (2016), p. 427 y ss.

${ }^{24}$ Para ULLEN (2015), p. 26: "el estudio del derecho conductual y del comportamiento resulta distintivo porque busca moldear el comportamiento humano en referencia a cierta medida de bien social. Esto lo distingue de otros campos basados en la manipulación para fines individuales, como la publicidad o el marketing; de otros campos orientados sobre el pensamiento antes que sobre la conducta, como la filosofia; y lo más importante, de otros campos conductuales basados en tratamientos descriptivos o evaluativos del comportamiento, como la antropología, sociología, psicología y economía que no necesariamente buscan controlar su objeto de estudio ni adentrarse en un análisis de política normativa". De hecho, como expone el citado autor, esta aproximación también ha sido objeto de crítica por parte de la doctrina económica y del análisis económico del derecho (p. 45 y ss.). De hecho, entre otros aspectos se le achaca (al igual que a la teoría de la elección racional) que (p. 53) también se basa en una tautología, "pues no distingue entre el comportamiento racional y el comportamiento irracional, $n i$ tampoco puede explicar por qué algunas personas son racionales en algunos aspectos de sus vidas e irracionales respecto de otros, mientras que otros son irracionales la mayor parte del tiempo y algunos racionales casi todo el tiempo". En la obra de THALER (2016) pueden encontrarse respuestas a muchas de estas objeciones. Y, una breve aproximación a los antecedentes de la economía conductual en QUINTANILLA (2002), p. 95 y ss. 
muchas veces depende de dónde fueron puestas en el momento de ser elegidas". Asumiendo este punto de partida, se evidencia que, si el sistema legal "permanentemente construye procedimientos, descripciones y contextos para llevar a cabo elecciones", puede advertirse que puede estar afectando a las preferencias y, por ende, a las valoraciones de los operadores jurídicos. De modo que "el Derecho puede construir, más que provocar, preferencias". Por ejemplo, en este sentido, siguiendo a SUNSTEIN (2012, 2, nota 16, p. 56) - que recoge el trabajo de REDELMEIER ROZIN y KAHNEMAN - "si se dijera que, de 400 personas que se someten a cierta operación, 350 están vivas después de 5 años, muchas más personas se someterían a la misma operación, que si se les dice que, de 400 personas que se sometieron a la operación, cincuenta murieron después de 5 años".

Ahora bien, también debe puntualizarse que, el hecho de que la Ciencia Económica no pueda explicarlo todo, no significa que no pueda explicar nada $a^{25}$. En efecto, aunque se descarte la perspectiva unidireccional que propone la lógica utilitarista, no debe concluirse la completa inadecuación de la metodología económica o de su capacidad analítica. Especialmente, si se tiene en cuenta que "la teoría económica ha utilizado profusamente instrumentos analiticos formales muy sofisticados para apuntalar sus tesis" 26. Como apunta THALER, "no es necesario echar por la borda todo lo que sabemos sobre el funcionamiento de las economías y los mercados", tales teorías (las basadas en el supuesto de que todo el mundo es un "Econ"), "no deberian ser descartadas, pues siguen siendo un útil punto de partida para la creación de modelos más realistas", pues, "lo que necesitamos es un enfoque más rico a la hora de llevar a cabo investigaciones económicas, uno que reconozca la existencia y la relevancia de los Humanos"27. Por ello, puede afirmarse que su utilidad no reside tanto en las posibilidades de describir detalladamente la realidad, sino "en la luz que puede ofrecer para plantear problemas, para preguntarse desde el modelo por qué la realidad es como es y para proponer medidas para mejorar la sociedad"28.

En definitiva, lo que este ensayo propone es "aprovechar" los avances que la economía (con todas sus limitaciones), la psicología y la neurociencia han alcanzado en los últimos años, para tratar de comprender las pautas del comportamiento humano y, desde esta perspectiva, identificar los elementos que permiten, de algún modo, predecir las decisiones de contratación de los empresarios. Todo ello, con el propósito de proponer cambios legislativos dirigidos a mitigar la acentuada segmentación de nuestro mercado de trabajo.

\footnotetext{
${ }^{25}$ CORONA (1993), p. 39.

${ }^{26}$ CALSAMigLiA (1987), p. 268.

${ }^{27}$ THALER (2016), p. 33.

${ }^{28}$ CALSAMIGLIA (1987), p. 268.
} 


\section{Sesgos y pautas del comportamiento empresarial e incidencia en las decisiones sobre las modalidades de contratación}

A partir del enfoque descrito en el apartado anterior, permítanme que vuelva a la primera de las cuestiones que les he formulado al inicio de este ensayo:

¿Por qué los empresarios no cumplen con las causas de temporalidad legalmente descritas?

$\mathrm{Y}$, teniendo en cuenta la perspectiva que ofrece la economía de la conducta, debería añadirse: ¿existe algún factor cognitivo que pueda explicar el comportamiento empresarial?

Como punto de partida y siguiendo el planteamiento de LAKOFF (2019, p. 15 y ss.) es importante tener en mente que cualquier palabra (en nuestro caso, "temporal" o "indefinido") evoca un "marco conceptual", que puede consistir en una imagen u otro tipo de información, creando un lenguaje (rico en metáforas) y unas ideas que encajan con nuestra forma de pensar. Y, desde el punto de vista empresarial, no es improbable que lo "temporal" se asocie con la flexibilidad, barato y competitividad; mientras que lo "indefinido" quede enmarcado en lo rígido, ineficiente y costoso. Y, ciertamente, el cambio de estos "marcos" (que describen actitudes y se plasman en conductas ${ }^{29}$ ) resulta particularmente complejo de combatir, pues, si los hechos no encajan con el marco existente, "rebotan" (no son interiorizados y, por consiguiente, difícilmente afectarán a las actitudes o a las conductas). De modo que nuestros conceptos no cambian simplemente porque alguien nos informe sobre determinados hechos. Si se pretende influir o persuadir a las personas de forma eficaz, es probable que deba afrontarse un cambio en los marcos. Y, esta es (sin duda) una tarea compleja (y ello podría ser una de las causas que explique el escaso éxito de las medidas contra la temporalidad).

En este sentido, creo que la experimentación llevada a cabo en el ámbito de la psicología conductual, puede ofrecer algunas luces sobre esta cuestión. Y, en concreto, los descubrimientos sobre la conducta humana y que atesoran los siguientes conceptos podrían ser claves:

"Costes de gestión; "Aversión a las pérdidas (y el efecto dotación)"; "Justicia y esfuerzo"; "El dolor de pagar"; "Problemas de autocontrol"; "Optimismo no realista (y la adaptación hedónica)"; "Disponibilidad"; "Conformidad"; y "Impronta, anclas e inercias".

\footnotetext{
${ }^{29}$ Sobre la distinción entre estos dos conceptos y la correlación entre ambos ver, OVEJERO BERNAL
} (2015), P. 
La matriz que estos vectores conceptuales describen, por un lado, podría contribuir al conocimiento de las razones por las que el Legislador ha sido incapaz de mitigar la temporalidad ilícita desde hace décadas; y, por otro, también nos pueden ofrecer valiosas pistas sobre nuestras reacciones previsibles ante la norma $\mathrm{y}$, por consiguiente, en aras a alcanzar de forma más eficaz sus objetivos, darnos luz sobre la arquitectura más adecuada de las reglas.

Veámoslos a continuación:

\subsection{El punto de partida: extinción contractual y costes de gestión}

El legislador, a la hora de fijar la indemnización legal tasada para cada una de las modalidades resolutorias, ha sido poco proclive a tener en cuenta los "costes de gestión" asociados a cada una de ellas ${ }^{30}$. Y, por consiguiente, no ha evaluado el impacto que éstos, conjuntamente con el respectivo coste monetario, tenían sobre el comportamiento de los destinatarios de las normas a la hora de optar por las diversas modalidades de contratación a su alcance. Y no cabe duda que el sumatorio de ambos elementos tiene un peso determinante en la toma de decisiones empresariales.

A mi entender, podrían catalogarse como "costes de gestión" los siguientes (entre otros): la necesidad de probar la "causa de empresa", los costes monetarios de la litigación y la dilación temporal e incertidumbre sobre el resultado final que todo proceso judicial lleva aparejado.

Desde este punto de vista, puede advertirse que la reforma de 2012, al disminuir el importe de la indemnización por despido improcedente (pasando de 45 a 33 días - y de 42 a 24 meses), facilitó que fuera más probable que la suma resultante de la indemnización de la resolución por "causas de empresa" (20 días) y los costes de gestión asociados superaran el importe del despido improcedente (33 días). En la medida que, con anterioridad, el diferencial podía ser de 25 días (esto es, 45 menos 20 en vez de los 13 actuales), este efecto era menos probable.

Lo que implica que la reforma de 2012 podría haber producido un efecto paradójico, pues, lejos de fomentar el recurso a la contratación indefinida (y el eventual recurso a la resolución por causas objetivas en caso de que se constatara un excedente de plantilla), podría haber acabado potenciando la contratación temporal (ilícita).

\footnotetext{
${ }^{30}$ Desde el punto de vista económico, estos costes han sido calificados como "costes ocultos" (TIROLE, 2018, p. 267).
} 
En efecto, esto podría ser así dado que con el cambio legislativo se ha reforzado a la resolución improcedente como la opción resolutoria preferida, por ser menos "costosa" que la objetiva procedente. Especialmente porque, aunque $a$ priori el importe es superior (33 días), la incertidumbre asociada es significativamente inferior y tiene menores costes de gestión (a pesar de que el "despido exprés" ya no sea posible). Es claro que, si el número de trabajadores afectados es elevado y/o la empresa no pudiera afrontar este mayor importe, la improcedencia podría no ser una opción "atractiva".

Al margen de estos últimos casos, la consecuencia derivada es que la contratación indefinida queda asociada (anclada) al importe de la indemnización por despido improcedente, disuadiendo a los empresarios a utilizarla (y exigiendo nuevas reformas legales para rebajar el importe - no se olvide - de un ilícito contractual), especialmente porque hay una alternativa más económica: el contrato temporal ilícito (y, sobre todo, la esperanza de que no será denunciado y la posibilidad de evitar los salarios de tramitación) $)^{31}$. Lo que está directamente relacionado la "aversión a las pérdidas" que se expone en el epígrafe que sigue.

En todo caso, en estas situaciones, se ha producido lo que se conoce como el "efecto desplazamiento" (HAMMOND, 2016, p. 152 a 156), pues, lejos de ser calificada como una responsabilidad derivada un ilícito contractual (y, por lo tanto, de un acto socialmente indeseable) es percibida como el pago a cambio del ejercicio de una facultad (la extinción sin causa). O, como apunta SANDEL (2013, p. 70), desde el punto de vista del comportamiento, la "multa" ha sido sustituida por la "tarifa". Lo que ha llevado a un sector de la doctrina laboral a entender que en nuestro ordenamiento jurídico existe un "despido libre indemnizado". Lo que no deja de ser muy controvertido (al menos, desde el punto de vista de la dogmática jurídica), pues, el hecho de que una persona esté dispuesta a asumir el coste de sus actos ilícitos no significa que tal conducta sea lícita (en definitiva, a mi entender, en este planteamiento subyace una cierta confusión entre el "coste de oportunidad" y la naturaleza jurídica de las instituciones laborales).

\subsection{La aversión a las pérdidas (y el efecto dotación)}

A partir de lo apuntado en el epígrafe anterior, la cuestión clave está en tratar de conocer los motivos por los que los empresarios acuden al contrato temporal sin respetar las causas de temporalidad. Especialmente cuando, como se sabe, en estos casos, el término no es suficiente para provocar la ineficacia contractual y, en consecuencia, esta opción tiene asociada un coste económico significativamente

${ }^{31} \mathrm{O}$, incluso (en el peor de los casos), se canalice a través de un falso autónomo o acudiendo a la economía informal. 
superior. En efecto, la contratación temporal ilícita acarrea (principalmente) con los siguientes costes monetarios:

- Pago de una indemnización de 33 días con un máximo de 24 meses;

- En caso de encadenamiento de contratos temporales, no pueden deducirse las compensaciones previas ex artículo 49.1.c ET (salvo la última ${ }^{32}$ );

- Puede imponerse una sanción administrativa; y, además,

- Acarrea también "costes de gestión"

Entonces, si finalmente pueden acabar pagando mucho más, ¿por qué se asume el riesgo de formalizar un contrato temporal ilícito?

Pues bien, es posible que lo que se conoce como "aversión a las pérdidas" podría explicar este comportamiento. Este concepto (propuesto, en el marco de la Teoría de la Perspectiva, por los psicólogos KAHNEMAN y TVERSKY, 1984, p. 570 y ss. ${ }^{33}$ ) implica que el malestar que experimenta una persona con una pérdida es casi el doble de la satisfacción que le produce una ganancia.

Lo que implica, como expone THALER (2016, p. 67 y 68), que los individuos son "amantes del riesgo en caso de las pérdidas", de modo que "están dispuestos a asumir el riesgo de perder más con tal de tener la oportunidad de poder no perder en absoluto" (aversión a las pérdidas) ${ }^{34}$. O, como apunta en otro momento (p. 431), "la

\footnotetext{
${ }^{32}$ SSTS 20 y 29 de junio 2018 (rec. 3510/2016; y rec. 2889/2016); 11 de julio 2018 (rec. 2131/2016); y 14 de febrero 2019 (rec. 1802/2017).

${ }^{33}$ Una extraordinaria descripción de los orígenes de estos autores y de la propia disciplina en LEWIS (2017).

${ }^{34}$ Probablemente, uno de los experimentos más famosos donde se evidencia este comportamiento es el planteado por TVERSKY y KAHNEMAN y que se conoce como el "problema de la enfermedad asiática" (y que, a su vez, evidencia la importancia de lo que - como se apuntará posteriormente - se conoce como "marcos" o "enmarcado"). Siguiendo la exposición de KAHNEMAN (2012, p. 479 y 480):

"Imagine que Estados Unidos se está preparando para el brote de una rara enfermedad asiática que se espera acabe con la vida de 600 personas. Se han propuesto dos programas alternativos para combatir esa enfermedad. Suponga que las estimaciones científicas más exactas de las consecuencias se los programas son las siguientes:

- Si se adopta el programa A, se salvarán 200 personas;

- Si se adopta el programa B, hay una probabilidad de un tercio de que 600 se salven y una probabilidad de dos tercios de que ninguna de ellas se salve.

Pues bien, la mayoría sustancial de los participantes eligieron el Programa A: preferían la opción cierta frente al juego. Los resultados de los programas vienen enmarcados de modo diferente en una segunda versión:

- Si se adopta el Programa A', 400 personas morirán.

- Si se adopta el Programa B', hay una probabilidad de un tercio de que nadie muera y una probabilidad de dos tercios de que 600 personas mueran.
} 
gente suele ser amante del riesgo en el ámbito de las pérdidas cuando tiene la oportunidad de recuperarlas" ${ }^{\prime 35}$.

En aras a reforzar esta idea, siguiendo la ilustrativa exposición de ARIELY y KREISLER (2018, p. 169), "tendríamos que ganar 20 dólares para igualar y contrarrestar el impacto emocional de perder 10 dólares". Y añaden, "debido a la aversión a las pérdidas, tendemos claramente a valorar las posibles pérdidas mucho más que las posibles ganancias". Lo que, desde un punto de vista puramente económico, no tiene excesivo sentido, pues, pérdidas y ganancias deberían ser consideradas como "socios financieros opuestos pero iguales y equivalentes".

La razón de esta reacción verificada a través de múltiples experimentos se debe a que reaccionamos más a los cambios que a los valores absolutos. Esta circunstancia tiene un efecto práctico extraordinario, pues, nos convierte en seres (mucho) más propensos al riesgo (nos arriesgamos más) cuando se trata de evitar pérdidas que cuando podemos optar a una ganancia. De hecho (HAMMOND, 2016, p. 73 a 75), tratando de identificar el origen de este comportamiento tan "humano", experimentaciones con monos "rhesus" han evidenciado también su aversión a las pérdidas, llevando a algunos investigadores a sugerir que esta tendencia irracional se remonta, tal vez, hasta 35 millones de años. Lo que sugiere que está profundamente "enraizada en nosotros y, por lo tanto, es muy difícil superar".

Si trasladamos esta hipótesis al ámbito laboral, podría explicar los motivos por los que los empresarios, asumiendo un alto riesgo, se vean "tentados o atraídos" a formalizar contratos temporales sin prestar excesiva atención a las causas de temporalidad ${ }^{36}$.

Observamos detenidamente y comparamos las dos versiones: las consecuencias de los Programas $A$ ' y A' son idénticas, lo mismo que las consecuencias de los programas $B$ y B'. Pero en el segundo marco, una mayoría eligió el juego (...). Las elecciones entre juegos y cosas seguras se deciden de forma diferente, dependiendo de si los resultados son buenos o malos. Las personas que deciden tienden a preferir la cosa segura frente al juego (sienten aversión al riesgo) cuando los resultados son buenos. Y tienden a rechazar la cosa segura y aceptar el juego (buscan el riesgo) cuando ambos resultados son negativos".

${ }^{35}$ En todo caso, conviene hacer un par de puntualizaciones relevantes. En primer lugar, como expone KAHNEMAN (2012, p. 383) en "los intercambios comerciales rutinarios no se da ninguna aversión a la pérdida”. Y, en segundo lugar, siguiendo a THALER (2016, p. 135), las pérdidas no producen "preferencias arriesgadas cuando no hay posibilidad de quedarse a cero" (esto es, no puede recuperarse lo perdido) y la aversión a las pérdidas es moderada cuando (por ejemplo, en un concurso, el casino o jugando a las cartas) se está ganando (y por consiguiente, "se juega con el dinero de la casa" - y no con el "propio"). En todo caso, como apunta KAHNEMAN (2013, p. 426), "Las condiciones límite para la aversión a las pérdidas todavía no se han definido con precisión".

${ }^{36}$ Siguiendo con el planteamiento de SUNSTEIN (2017, p. 34) adaptado a nuestro objeto de estudio, téngase en cuenta que, en la medida que el Legislador asocia la contratación temporal ilícita al abono de un monto económico, no está propiamente "invalidando" una opción, pues, sigue existiendo la posibilidad 
En efecto, a pesar del elevado coste que formalmente acarrea esta opción, la existencia de una posibilidad (por remota que sea) que permita eludir la indemnización de 33 días (opción, como se ha apuntado, preferida a la resolución por causas objetiva procedente) justifica la asunción del mayor riesgo que implica formalizar contratos temporales ilícitos. Con tal de evitar el coste del despido improcedente, asumen el riesgo porque cabe la posibilidad (ex artículo 49.1.c ET) de que no tengan que pagar nada (para un contrato de interinidad, por ejemplo ${ }^{37}$ ) o sólo se tenga que pagar 12 días- o, incluso, 20 días si hubiera llegado a consolidarse la doctrina de Diego Porras (1) a todos los contratos temporales.

La poderosa aversión a las pérdidas podría erigirse en una explicación plausible de esta pauta de comportamiento. Aunque no es la única, pues, como se analizará en los epígrafes que siguen, hay otros factores de diversa naturaleza que, en hipótesis, podrían contribuir también a explicar el recurso a la contratación temporal ilícita o, mejor dicho, a consolidarla o, incluso, potenciarla significativamente.

Por otra parte, y para complementar lo anterior, es importante tener en cuenta que la aversión a las pérdidas tiene una estrecha relación con lo que se conoce como "efecto dotación". En síntesis (THALER, 2016, p. 47), este concepto se refiere a que "la gente valora más las cosas que ya forman parte de su dote que las cosas que podrían pasar a formar parte de ella, disponibles, pero aún no adquiridas". Se trata, por tanto, de una discrepancia entre "precios de compra y precios de venta" (p. 49), de modo que valoramos más lo que tenemos que lo que un estaríamos dispuestos a pagar si tuviéramos que comprarlo. Por ejemplo, tendemos a valorar más nuestra casa (o una entrada de nuestra banda favorita de jazz) que lo que estaríamos dispuestos a pagar si pudiéramos comprarla. Desde este punto de vista, es clara la relación de este concepto con la aversión a las pérdidas, pues, (ARIELY y KREISLER, 2018, p. 169) "no deseamos renunciar a nuestras cosas en parte porque las sobrevaloramos, y sobrevaloramos nuestras cosas en parte porque no deseamos renunciar a ellas" ${ }^{\prime 38}$. Y,

de elegir hacer el contrato ilícito y asumir el consiguiente coste (en estos casos, la elección no queda "invalidada"). Y aunque somos conscientes que esta conducta puede producir daños a terceros (al menos, al trabajador directamente afectado) se admite. En cuanto, a si el importe indemnizatorio efectivamente compensa los daños sufridos me remito a lo que se expondrá posteriormente.

${ }^{37}$ STS 13 de marzo 2019 (rec. 3970/2016).

${ }^{38}$ Siguiendo a ARIELY y KREISLER (2018, p. 161), en correspondencia a lo apuntado en relación a aversión a las pérdidas, conviene tener en cuenta que "en promedio, en los experimentos sobre el efecto dotación, los precios de venta suelen ser aproximadamente el doble de los precios de compra". Incluso, ARIELY (2008, p. 155) entiende que el efecto dotación "no se limita a las cosas materiales", pues, "también puede aplicarse a los puntos de vista". De modo que una vez que asumimos un punto de vista lo "amamos quizás más de lo deberíamos. La apreciamos en más de lo que vale". Lo que explicaría los problemas para abandonarlo. Este efecto también recibe el nombre de "sesgo de perseverancia en la creencia (OVEJERO BERNAL, 2015, p. 64). En todo caso, debe puntualizarse, siguiendo con 
ciertamente, la incidencia de este concepto en el objeto de este estudio, como se analizará con posterioridad, podría ser particularmente significativa, por ejemplo, en la mayor o menor propensión de los trabajadores a accionar judicialmente al finalizar un contrato temporal ilícito.

\subsection{Justicia y esfuerzo}

La justicia y el esfuerzo está en estrecha relación con la aversión a las pérdidas recién descrito. Según los autores ARIELY y KREISLER (2018, p. 189), a menudo el precio que estamos dispuestos a pagar por algo que acabamos comprando (o no) depende, en gran medida, de lo justo que nos parezca el precio $^{39}$. Y, en hipótesis, podría ser que el método para la determinación de las indemnizaciones por la extinción del contrato (especialmente en caso de improcedencia) pueda verse afectada por este fenómeno.

En la evaluación de una transacción (siguiendo con los citados autores), lejos de los modelos económicos tradicionales, que se limitan a comparar el valor con el precio, las personas (humanos) también tienen en cuenta otros elementos, como la justicia: "a la gente puede no gustarle la solución económica perfecta y eficiente cuando le parece injusta, y esa sensación la tenemos todos incluso cuando la transacción tiene sentido, e incluso cuando obtendríamos una gran utilidad por ello". Para KAHNEMAN (2012, p. 399) "la utilización del poder del mercado para imponer pérdidas a otros es inaceptable".

De hecho, siguiendo de nuevo con ARIELY y KREISLER (2018, p. 190), esta sensación es especialmente acusada cuando "tenemos que pagar un precio elevado por algo que parece fácil de hacer o que lleva poco tiempo" (por ejemplo, nuestra reacción al pagar el precio que nos cobra un cerrajero tras abrir la puerta en cuestión de segundos).

KAHNEMAN (2012, p. 383), que "el efecto dotación no es universal. Si alguien nos pide que le cambiemos un billete de 5 dólares por cinco de uno, le daremos esos cinco sin sensación de pérdida alguna". En otro orden de consideraciones, es importante tener en cuenta que el efecto dotación (y la aversión a las pérdidas) cuestiona (muy seriamente) la validez del Teorema de Coase (en apretada síntesis: si no hay costes de transacción y los derechos de propiedad están bien definidos, la asignación eficiente de los recursos se produce con independencia de la asignación inicial de los derechos, porque los derechos se trasladan a su uso más valorado). Esto es así, porque, a diferencia de lo que sostiene el Teorema, la distribución inicial sí tiene una influencia decisiva en la distribución final (produciéndose una significativa reducción en el número de intercambios con respecto a los que el Teorema sugiere que se deben producir). Una aproximación al respecto en, THALER (2016), p. 361 y ss.; KAHNEMAN (2003), p. 191 y ss.; y, brevemente, SUNSTEIN (2012, 2), p. 56 y 57; y ULLEN (1999), p. 810 y 811.

${ }^{39}$ Extensamente al respecto también, THALER (2016), p. 193 y ss. 
Esta reacción se produce "porque nos creemos que los precios deberían ser justos, y rechazamos la utilidad cuando pensamos que es injusta (incluso, aunque nos acabe perjudicando y con independencia de que podemos permitírnoslo o no $)^{40}$. Incluso (p. 194), nuestras reacciones pueden estar motivadas por puro rencor o venganza (sin importarnos si efectivamente existen razones legítimas para elevar el precio).

Y, a la hora de determinar la justicia de un precio que se nos pide pagar por algo (p. 196 y 197), es común que nos guiemos por una evaluación del nivel de esfuerzo que se ha dedicado para ello ${ }^{41}$. Percibimos que los precios altos quedan justificados (nos sentimos

${ }^{40}$ Como exponen los citados autores (p. 192), a propósito de lo que se conoce como el "juego del ultimátum", los investigadores han descubierto que en las ofertas injustas se activan unas partes del cerebro distintas a cuando son justas. En efecto (siguiendo a ARIELY, 2011, p. 121), en estos casos, la decisión de castigar a los otros, aunque nos cueste algo, está asociada a un sentimiento de placer y tiene un fundamento biológico. Siguiendo la exposición de $\operatorname{SUNSTEIN~}(2012,2,60)$, la dinámica de este juego es la siguiente: "La gente que dirige el juego reparte algo de dinero, de manera provisional, al primero de dos jugadores. El primer jugador debe darle una parte de ese dinero al segundo jugador. Si el segundo jugador acepta esa cantidad, puede quedarse con lo que le es ofrecido, y el primer jugador se queda con el resto. Pero si el segundo jugador rechaza la oferta, ninguno de los jugadores se queda con nada. A ambos jugadores se les informa que éstas son las reglas. No se admiten negociaciones. Valiéndose de supuestos estándar acerca de la racionalidad, el interés propio, y la elección; los economistas predicen que el primer jugador debe ofrecer un centavo y que el segundo jugador debe aceptar. Pero esto no es lo que sucede. El promedio de las ofertas usualmente está entre el 30\% y el 40\% del total. Las ofertas menores al 20\% a menudo son rechazadas. Muchas veces hay una división de 5050". La implicación de este comportamiento es particularmente relevante, pues, a diferencia de lo que sostiene la Teoría de la Elección Racional, (ULLEN, 1999, p. 810) "la gente está mucho más dispuesta a cooperar y que tienen un sentido mucho más fuerte de lo que es un resultado equitativo". Aunque como expone KAHNEMAN (2013, p. 421), "Otros estudios aclaran que ofertas que serían rechazadas al provenir de una persona serían aceptadas al originarse en una computadora".

${ }^{41}$ p. 196: "la evaluación del nivel de esfuerzo que se ha dedicado a algo es un atajo muy común que solemos utilizar para valorar la justicia del precio que se nos pide pagar por algo". Aunque, como expone THALER (2016, p. 197), también depende del "marco en el que se encuadre" (como se ha evidenciado anteriormente con la exposición del experimento de la "enfermedad asiática"). El "enmarcado" (KAHNEMAN, 2012, p. 120) se refiere al hecho de que "maneras diferentes de presentar la misma información a menudo provocan emociones diferentes. La afirmación de que 'las posibilidades de supervivencia un mes después de la cirugía son del 90 por ciento’ hace que nos sintamos más seguros que la de que 'la mortalidad un mes después de la cirugía es del 10 por ciento". De modo que (p. 354) "variaciones intranscendentes en la formulación de un problema" causan grandes cambios de preferencias, ofreciendo (p. 430) relevantes oportunidades de manipulación (para quien quiera explotarlas con un determinado fin). O, como apunta KAHNEMAN (2003, p. 197 y 198) - citando un trabajo de SCHELLING - el hecho de enmarcar plantea, sin duda, dilemas (pues, "aumenta la accesibilidad de algunas respuestas y hará que otras sean menos probables"). De hecho (SUNSTEIN y THALER, 2009, p. 54) el "enmarcado funciona porque tendemos a tomar las decisiones de forma negligente y pasiva. Nuestro sistema reflexivo no hace el trabajo que sería necesario para comprobar si enmarcando las preguntas de otra forma, la respuesta sería distinta". Esto es (p. 56), en general, los Humanos, al estar muy ocupados y no prestar mucha atención, aceptan las preguntas como se las plantean en vez de intentar determinar si sus respuestas variarían si se las formularan de otra manera". Lo que tiene una gran 
mejor) si lo que tenemos que pagar ha costado más esfuerzo y éste es evidente - esto es, que tenemos la impresión de que su ejecución es muy difícil de hacer (llevándonos, en ocasiones, a pagar más por la incompetencia ${ }^{42}$ ).

Precisamente, la transparencia del esfuerzo invertido es un factor esencial para ayudarnos a evaluar la justicia de un precio (p. 201 y 202). Es posible que al aumentar el nivel de transparencia y, con ello, hacer el esfuerzo más evidente, inconscientemente nos sintamos mejor a la hora de pagar lo que nos piden.

Y es en este nivel del análisis que, en hipótesis, las indemnizaciones legales tasadas y, especialmente, las más elevadas (como en los casos de improcedencia), podrían estar suscitando un especial rechazo por parte de los empresarios. Repárese que estos importes no compensan efectivamente el daño real sufrido (se resarce in re ipsa ${ }^{43}$ ) y, por consiguiente (aunque se conocen los parámetros de cálculo - salario/tiempo), es imposible conocer si efectivamente se produce una compensación por exceso o por defecto $^{44}$.

En definitiva, podría entenderse que hay una clara falta de transparencia en la determinación del importe indemnizatorio, lo que podría estar reforzando la aversión a las pérdidas anteriormente descrita.

relevancia, pues, es ilustrativo de la inconsistencia de las preferencias (también visible en las situaciones de elección por defecto).

42 "En la práctica, cuando valoramos más el esfuerzo que el resultado, lo que estamos pagando es la incompetencia, y aunque esto es algo irracional, al parecer nos sentimos más racionales y más cómodos pagando por esa incompetencia”. ARIELY y KREISLER (2018), p. 198.

${ }^{43}$ En efecto, por motivos de economía procesal, se resarce por el mero incumplimiento contractual, sin entrar a valorar la entidad del daño efectivamente sufrido por el trabajador.

${ }^{44}$ De hecho, SUNSTEIN (2012, 2, p. 57 y 58), refiriéndose a la responsabilidad extracontractual, plantea que la aversión a las pérdidas plantea "serias preguntas" respecto a su objetivo, pues, ¿debe hacerse conforme a la preservación del "statu quo anterior al daño causado"?; o bien, ¿debe "ser el reflejo de la cantidad que una parte pediría para someterse al daño antes del hecho"? Conflicto que, a mi entender, sería perfectamente extrapolable al ámbito laboral y a los casos de extinción contractual (y muchos otros). Desde otro punto de vista, repárese que el "efecto dotación" (y la aversión a las pérdidas consiguiente) también puede proyectarse con respecto al derecho de los trabajadores a mantener su empleo salvo la concurrencia de una causa. De modo que la indemnización legal tasada podría estar desajustada con respecto a lo que los trabajadores estiman que deberían percibir en caso de ser despedidos sin causa, o bien, en relación a lo que los empresarios estiman que deberían pagar por ello. El eventual derecho a una prestación por desempleo en estos casos, en hipótesis, podría compensar la valoración de los trabajadores no satisfecha por la indemnización (sin perjuicio de que, como se apuntará posteriormente, describe un sistema de fraccionamiento del coste o de "división del dolor de pagar"). No obstante, el hecho de que la prestación por desempleo se perciba con independencia de la causa resolutoria y de su calificación judicial, dificulta la labor de su calificación conforme a estas categorías conceptuales. 


\subsection{El dolor de pagar}

Los seres humanos, siguiendo a ARIELY y KREISLER (2018, p. 102 a 105), experimentamos dolor al pagar. En efecto, "experimentamos algún tipo de dolor mental cuando pagamos por las cosas" y, lejos de proceder del gasto en sí mismo, lo hace de la idea de gasto. Hasta el extremo que, cuanto más pensamos en ello, más intenso es el dolor.

Y esta dimensión podría ser determinante en el ámbito objeto de estudio, porque la existencia de importes indemnizatorios tasados vinculados a ciertas extinciones contractuales (y cuyo coste es anticipable), sugiere que la previsión del ahorro podría ser un buen instrumento para afrontar (atenuar) el dolor que padecemos. Y, obviamente, su fomento (incluso mediante incentivos fiscales) podría llegar a ser un objetivo de política legislativa (en aras a disipar los temores hacia la contratación indefinida y los temidos costes en caso de tener que llevar a cabo una reestructuración de la plantilla).

Para comprender mejor el potencial de esta dimensión, es importante tener en cuenta que este dolor es "el resultado de dos factores distintos: el primero es el tiempo que transcurre entre que el dinero sale de nuestra cartera y que consumimos el producto que hemos pagado; y el segundo es la atención que prestamos al pago en sí mismo". Lo que significa que podemos aliviar este dolor aumentando la brecha temporal entre pago y consumo ( si están separados no prestamos atención al pago) y/o reduciendo la atención necesaria para realizar el pago en sí mismo.

Pues bien, diversos experimentos han evidenciado (ARIELY y KREISLER, 2018, p. 111), que, pudiéndose efectuar el pago antes, durante o después de consumir un producto, "el momento concreto en que se paga por algo influye en nuestras decisiones, y, lo que es más importante, cuando la sensación de pagar está especialmente presente, alteramos radicalmente nuestro patrón de gasto". Lo que significa que "debido al dolor que sentimos al pagar, estamos dispuestos a pagar más antes, menos después, y aún menos durante el consumo del mismo producto".

Al pagar antes de consumir - esto es, por anticipado - (p. 112 y 113), el consumo parece "casi indoloro", pues, "en el momento del consumo ya no hay que pagar ni preocuparse por un pago futuro". Además (p. 114), una vez que el dinero ya está asociado a una categoría ("ahorro para indemnizaciones"), tenemos la impresión de que ya se ha pagado. Es como si no se estuviera utilizando el dinero propio, de modo que "nos sentimos menos culpables por gastarlo". 
En este sentido, el concepto de "contabilidad mental" resulta muy interesante. Siguiendo con SUNSTEIN y THALER (2009, p. 67 a 69), a pesar de que el dinero es "fungible" y, por consiguiente, carece de restricciones de uso, los humanos recurrimos a la contabilidad mental (violando la fungibilidad del dinero) para controlar el gasto. En definitiva, sin negar el carácter sensato y comprensible de este modo de proceder, creamos (mental o realmente) cuentas "estancas" a las que les atribuimos usos exclusivos a cada una (impidiendo la reasignación a otros - a pesar de que, en ocasiones, pueda llevarnos a tomar malas decisiones ${ }^{45}$ ).

Este comportamiento, no obstante, no tiene porqué ser, en sí mismo, negativo. Siguiendo con ARIELY y KREISLER (2018, p. 77 y 78), en la medida que el ser humano no tiene una capacidad de cálculo financiero, "es extremadamente difícil evaluar los costes de oportunidad y las múltiples posibilidades de cada transacción financiera"46. De modo que "la contabilidad mental nos ofrece una heurística útil -o atajo mental - para tomar decisiones". Especialmente porque el coste de oportunidad asociado a cada transacción queda acotado al uso de la cuenta a la que hemos decidido que pertenece (en vez de proyectarse sobre todas las opciones posibles). Así pues, "cuando compartimentamos para simplificar, cada vez que gastamos dinero no tenemos que pensar en todos los costes de oportunidad existentes, pues ello sería totalmente agotador".

De modo que ahorrar con un propósito predeterminado (por ejemplo, ante una eventual reestructuración de plantilla) puede contribuir a disipar el dolor a pagar (y, por consiguiente, difuminar las resistencias a hacer un contrato indefinido).

No obstante, la aversión a las pérdidas y nuestro "cortoplacismo" (esto es, nuestra dificultad de ver o proyectar más allá de lo inmediato - a la que se hará referencia en el epígrafe que sigue), pueden dificultar la decisión de ahorrar. De ahí que el establecimiento de bonificaciones fiscales y/o bien el fomento del ahorro empresarial vinculado a situaciones en las que se obtienen beneficios empresariales podrían contribuir a persuadir a los empresarios neutralizar estos efectos ${ }^{47}$.

\footnotetext{
${ }^{45}$ Ver también al respecto THALER (2016), p. 122 y ss. De hecho, retomando un comentario anterior sobre la moderada aversión a las pérdidas en las situaciones de juegos en las que se está ganando, el hecho de que "se esté apostando con el dinero de la casa" (o con "dos bolsillos" - el dinero traído de casa y el ganado jugando) es un claro ejemplo de contabilidad mental (pues, el dinero - en tanto que fungible no deja de ser "todo nuestro"). Ver al respecto el citado autor (p. 130 y ss. y 415).

${ }^{46}$ En síntesis, (THALER, 2016, p. 45) "el coste de oportunidad de cualquier actividad es aquello que a lo que se renuncia para llevarla a cabo".

${ }^{47}$ Lo que no dejaría de ser una "adaptación" de lo que THALER (2016, p. 427 y ss.) denomina como "ahorre más mañana". Ver también, entre otros, AKERLOFF (2002, p. 28 a 31). De hecho, siguiendo con THALER (2016, p. 119) es posible que determinados bienes adquiridos anticipadamente no sean
} 
En paralelo, es claro que el fraccionamiento del coste (o la "división del dolor" "48) contribuye a disipar este dolor, no obstante, en el marco del contrato de trabajo, dados los efectos contraproducentes que puede provocar (relajando el nivel de cuidado al no internalizar todas las consecuencias derivadas del ilícito contractual ${ }^{49}$ ), parece razonable que esta opción sólo pueda plantearse en los casos de despido objetivo procedente (y no en caso de improcedencia) $)^{50}$.

\subsection{Problemas de autocontrol}

Si la formalización de un contrato temporal ilícito puede ser sustancialmente más costosa, ¿por qué los empresarios no anticipan este riego (y actúan lícitamente desde un principio)?

Dejando de lado la cuestión relativa a la valoración subjetiva sobre la probabilidad de ser sancionado (a la que se hará referencia posteriormente), es posible que este comportamiento pudiera estar influenciado por el efecto de lo que se conoce como "sesgo hacia el presente"

Esta heurística se caracteriza porque (TIROLE, 2018, p. 139) tenemos una preferencia demasiado fuerte por el presente (o falta de voluntad), llevándonos a la procrastinación, "a dejar para más adelante las tareas desagradables, a no invertir demasiado en el futuro, a tener comportamientos impulsivos". De hecho, esto contradice una de las máximas de la teoría de la elección racional (de hecho, es un elemento particularmente perturbador para la misma y sus seguidores), pues, sin la aparición de nueva información, no deberíamos cambiar nuestros planes. En definitiva, en algunas

percibidos como un gasto, sino como una inversión. De modo que, al consumirlos, se perciba que son gratis o mucho menos costosos (lo que, ciertamente, no deja de evidenciar un "comportamiento mental bastante inconsistente"). La clave, en el marco de la extinción contractual, en hipótesis, estaría en desvincular el desembolso económico de la ineficacia contractual, mediante el ahorro anticipado.

${ }^{48}$ ARIELY y KREISLER (2018), p. 130. Autores que apuntan que cuando los costes se reparten entre diversas personas (por ejemplo, una cena) en tales casos se tiende a consumir más.

${ }^{49}$ Sobre esta cuestión ver también TIROLE (2018), p. 263. Autor que, para las resoluciones por causas de empresa, sugiere como solución la imposición de una multa a las empresas por cada despido a cambio de la "reducción de las cotizaciones destinadas a desempleo y de una agilización de los trámites administrativos y judiciales por despido" (p. 268).

${ }^{50}$ Como, por ejemplo, llevaba a cabo el FOGASA en las empresas de menos de 25 trabajadores. Como se sabe, esta posibilidad ya no es posible (Ap. 8 del artículo 33 ET suprimido con efectos de 1 de enero de 2014 y vigencia indefinida por disp. final 5 de Ley 22/2013). En cualquier caso, como se ha apuntado, el eventual derecho a la prestación por desempleo, también describe una medida de fraccionamiento (aunque, en hipótesis, podría ser calificada como un instrumento para mitigar el efecto dotación de los trabajadores con respecto al derecho a no ver extinguido el contrato sin causa).

${ }^{51}$ O, en su formulación más técnica, "descuento cuasihiperbólico" (THALER, 2016, p. 145 y 146). 
elecciones intertemporales, la autoridad de nuestro "Sistema 2" queda en entredicho por la rapidez del "Sistema 1".

Así pues, esto significa que preferencias en un "tiempo 1" (en nuestro caso, celebración de un contrato temporal a sabiendas ilícito), divergen de las preferencias que se tienen más tarde en un "tiempo 2" (tener que abonar todos los costes asociados a dicha ilicitud). Es decir, en un contexto de decisión intertemporal, experimentamos inconsistencias temporales dinámicas (y, por tanto, dejamos de ser racionales); o, lo que es lo mismo, tenemos un "problema de autocontrol". Y ello se traduce en la comisión de errores de juicio ${ }^{52}$, pues, estas elecciones iniciales pueden acabar teniendo efectos dañinos graves más tarde en el tiempo. Lo que sugiere que, quizás, estas situaciones se caractericen por el prodominio del "Sistema 1" (mostrando claramente su "miopía").

Así pues, para poner un ejemplo que ayude a ilustrar esta idea, llevados por nuestras emociones, nos cuesta muchos renunciar hoy la compra de bienes (no "esenciales") en vez de, por ejemplo, ahorrar para nuestra jubilación ${ }^{53}$.

En definitiva (THALER, 2016, p. 161, 162 y 173), tendemos a valorar más el consumo presente que el futuro, de modo que tenemos problemas para gestionar la "gratificación aplazada". De hecho, modificamos con cierta frecuencia nuestras preferencias, "[cambiando] de opinión respecto a lo previsto" 54 . O, como apuntan ARIELY y KREISLER (2018, p. 267) "nos cuesta mucho resistir la tentación, incluso aunque sepamos muy bien qué es lo que conviene y lo que nos estamos jugando" 55 .

Este cortoplacismo, tan característico de nuestro día a día, proyecta una especie de túnel cognitivo (un enfoque muy estrecho), que nos dificulta ver o proyectar más allá de lo

\footnotetext{
${ }^{52}$ Una exposición de la actividad cerebral que se produce en estos casos en, SUNSTEIN (2014), p. 64 y 65.

${ }^{53}$ Otro ejemplo (adaptando la exposición de ARIELY y KREISLER, 2018, p. 259), si hoy nos dan a elegir entre tarta o plátano para la cena de Navidad de dentro de 3 meses, si aspiramos a estar más sanos, probablemente escogeremos la fruta. No obstante, el día de la cena es probable que nos apetezca más la tarta y cambiemos nuestra preferencia.

${ }^{54}$ En este sentido THALER (2016, p. 173) entiende que "la mayoría de nosotros somos conscientes de tener problemas de autocontrol, pero muchas veces subestimamos su severidad, por lo que puede decirse que somos ingenuos respecto a nuestro propio nivel de sofisticación".

${ }^{55}$ Un estudio clásico para los investigadores del autocontrol es (siguiendo a THALER, 2016, p. 158) el episodio de La Odisea de Homero relativa a Ulises y las sirenas. Y, en concreto, a las medidas adoptadas por éste (atándose al mástil y tapando con cera los oídos de la tripulación) para poder escuchar sus irresistibles cantos sin caer en la trampa de acercar el barco a las rocas donde estaban (evitando, pues, encallarse y ahogarse) y así poder seguir vivo.
} 
inmediato y es especialmente acusado en situaciones de escasez ${ }^{56}$. Y ello puede provocar lo que ARIELY y KREISLER (2018, p. 267) describen como un problema de confianza entre nuestro yo presente y nuestro yo futuro: "el yo futuro (...) confía en que su yo presente renuncie a algunas recompensas inmediatas [para prevenir un riesgo, como por ejemplo, la jubilación], mientras que [el] yo presente confía en que su yo futuro tome decisiones más inteligentes y abnegadas sobre [esa mismo propósito]. (...) [E]s igual de imprudente e insensato confiar en que nuestro yo pasado haya resistido la tentación que confiar en que nuestro yo futuro lo vaya a hacer".

A la luz de lo expuesto, es posible que este fenómeno pueda tener algún tipo de incidencia en el comportamiento empresarial a la hora de formalizar contratos indefinidos. Y, en estos casos, (siguiendo a SUNSTEIN, 2017, p. 27) el incremento de la información institucional sobre los límites de la contratación temporal y de los costes de su incumplimiento se erigen en un poderoso instrumento para superar la procrastinación (y de este modo fortalecer la "autoridad" del "Sistema 2"). Las medidas dirigidas a fomentar el ahorro, anteriormente expuestas, también pueden ayudarnos a evitar este cortoplacismo. Sin olvidar que, como se ha avanzado, la cuestión relativa a la probabilidad de imponer una sanción en caso de comportamiento ilícito es un aspecto estrechamente relacionado y, sin duda, también determinante. Este aspecto se abordará a continuación.

\subsection{Optimismo no realista (y la adaptación hedónica)}

Un factor poderoso que, combinado con los anteriores, puede contribuir a explicar el comportamiento empresarial descrito en los epígrafes anteriores es lo que se conoce (SUNSTEIN y THALER, 2009, p. 49 y 50) como "optimismo no realista". Esto es, el (irracional) exceso de confianza (por ejemplo, cuando los empresarios subestiman la probabilidad de ser demandados o sancionados por la celebración de un contrato temporal ilícito) ${ }^{57}$.

${ }^{56}$ HAMMOND (2016), p. 198 a 203. Por ejemplo, este efecto podría influir poderosamente en las decisiones de los autónomos en sus primeros estadios profesionales y la tendencia a pagar las cuotas más bajas posibles (en perjuicio de sus intereses a largo plazo).

${ }^{57}$ Este sesgo (KAHNEMAN, 2003, p. 118 a 120) es el resultado de un "salto a las conclusiones sobre la base de una evidencia limitada" (provocado, principalmente, por el hecho de que el "Sistema 2" perezoso - "aprobará muchas creencias intuitivas que reflejan directamente las impresiones generadas por el Sistema 1"). Y el hecho de lo que vemos es todo lo que hay ("what you see is all there is" WYSIATI), nos permite "pensar con rapidez y que seamos capaces de dar sentido a cierta información parcial en un mundo complejo". No obstante, esta "poderosa regla" da pie a diversos y variados sesgos en juicios y elecciones (como el "exceso de confianza", el "efecto marco" - ver infra -, entre otros). Porque, tomamos decisiones a partir de la escasa y cualitativamente pobre información de que disponemos, dándola como omnicomprensiva, obviando la existencia de más datos, porque el "Sistema 1", automáticamente la procesará como si fuera verdadera (p. 204). Con el añadido que, si la historia es 
Se trata, sin duda, de un rasgo universal de los humanos. Si bien nos permite tener un enfoque positivo de la vida (ayudándonos a ser más felices y estar más satisfechos), tiene un grave riesgo ${ }^{58}$. Tendemos a asumir más riesgos individuales porque sobreestimamos nuestra inmunidad personal y, por ello, tendemos a dejar de tomar medidas preventivas razonables (o adoptamos precauciones insuficientes) ${ }^{59}$. Este optimismo está estrechamente relacionado ${ }^{60}$, por un lado, con el "sesgo de la confianza excesiva" (sobreestimamos la precisión de nuestros juicios y nuestras creencias); y, por otro las, con el "sesgo de la ilusión de control" (sobreestimamos el grado de controlabilidad que creemos tener - por ejemplo, en la predicción y control de nuestro ambiente).

A su vez, siguiendo a ULLEN (2015, p. 34) - que recoge las conclusiones de los estudios sobre psicología y economía de la felicidad -, nuestra "predicción afectiva", esto es, la habilidad humana para predecir estados emocionales futuros (placer o el dolor que algún bien o evento aún no experimentado nos dará) es "muy mala". Por ello (p. 41), las personas son propensas a tomar decisiones que no les beneficien, lo que implica que "no necesariamente lograrán mejores predicciones emotivas con el tiempo o la experiencia" "61. Sin olvidar (TALEB, 2011, p. 27) que no sólo somos incapaces de predecir las rarezas (y, por ende, el curso de la historia), sino que tampoco tenemos conciencia sobre nuestros errores de previsión. Y esto está muy relacionado con el sesgo de disponibilidad al que se hará referencia en el epígrafe que sigue.

buena, nos la creemos (p. 263) e, incluso, podemos llegar a creernos aquellas que nos hemos inventado nosotros mismos (p. 205).

${ }^{58}$ OVEJERO BERNAL (2015), p. 86.

${ }^{59}$ Como exponen los citados autores (p. 50), el mero recuerdo de un acontecimiento malo puede ser un factor que contribuya a rebajar nuestro optimismo (y, por ende, a ser más precavidos). Ver también SUNSTEIN (2017), p. 30 y ss. Y, en situaciones emocionalmente muy intensas, además, tendemos a experimentar lo que se denomina como el "descuido de la probabilidad". Esto es, (SUNSTEIN, 2006, p. 15 y 16), "cuando se desatan fuertes emociones, la gente tiende a centrarse en el caso peor y no piensa en absoluto acerca de cuestiones de probabilidad". De modo que la "gente se muestra altamente sensible a los resultados", y "variaciones significativas en su probabilidad no afectan mucho el pensamiento y la conducta". De modo que, en estos casos, nos fijamos principalmente en lo bueno o malo de un resultado, pero no en la probabilidad de que haya un resultado bueno o malo.

${ }^{60}$ OVEJERO BERNAL (2015), p. 67.

${ }^{61}$ Siguiendo con THALER (2016, p. 89 a 91), en la medida que a la economía del comportamiento se le ha achaca que está apartada de la realidad, pues, basa sus conclusiones a partir de experimentos de laboratorio que sólo se repiten una vez (mientras que "en el 'mundo real' las personas tienen varias oportunidades que les permiten aprender de los errores"), en función de la frecuencia a la que nos sometemos a decisiones menos o más importantes (desde comprar el pan hasta elegir un coche, una casa o una pareja sentimental), "dado que el aprendizaje requiere práctica, y que por defecto la práctica se obtiene con más frecuencia en situaciones de poco riesgo [como comprar el pan], es más probable que la gente tome las decisiones acertadas cuando hay poco riesgo que cuando hay mucho". 
Y, quizás, como se ha avanzado, los empresarios podrían experimentar este fenómeno ${ }^{62}$. $\mathrm{Y}$, no cabe duda que esta percepción puede estar alimentada por el hecho de que los trabajadores temporales son poco propensos a accionar judicialmente contra el empresario en estos casos (tendencia que probablemente se haya visto sustancialmente acrecentada desde que, tras la reforma de 2012, ya no se devengan salarios de tramitación). Y, la "adaptación hedónica" ${ }^{\prime 3}$ o el proceso de estabilización emocional que hace que percepciones positivas (o negativas) desaparezcan, también podría ser un factor que podría explicar la asimilación de la precariedad por parte de los trabajadores $\mathrm{y}$, por consiguiente, una cierta propensión a mantener el statu quo (y no accionar judicialmente o denunciar su situación) ${ }^{64}$.

Desde este punto de vista, en aras a hacer realidad la amenaza de sanción que contribuya a disipar este optimismo no realista empresarial, la posibilidad legal de reclamar salarios de tramitación en la contratación temporal ilícita podría erigirse en una hipotética medida correctora. En efecto, en la medida que incrementaría los incentivos de los trabajadores a accionar judicialmente, podría convertirse en un poderoso incentivo empresarial para ajustarse a las causas lícitas de temporalidad (al hacer más creíble el riesgo asociado a su conducta contractualmente ilícita ${ }^{65}$ ). Es claro que una mayor intervención inspectora por parte de la ITSS también contribuiría, pero teniendo en cuenta el número de efectivos es poco probable que tuviera la misma eficacia (salvo que se utilizaran instrumentos que posibiliten la escalabilidad - como, por ejemplo, los basados en big data).

Por otra parte, es posible que la aversión a las pérdidas que experimentan los trabajadores también pudiera jugar un papel importante para explicar este fenómeno (o, al menos, en hipótesis, sugiere una posible descripción del mismo). Al finalizar el contrato, la complejidad con respecto a la conceptuación de las causas de temporalidad (y su interpretación jurisprudencial) podría dificultar que puedan evaluar si efectivamente se ha respetado (o no) el marco legal y, por consiguiente, no tengan suficiente información sobre si efectivamente tienen un derecho exigible (de modo que, no se produciría el efecto dotación - al que se ha hecho referencia anteriormente - al "no nacer la expectativa de un derecho"). Ello dificultaría que pudieran aventurarse a iniciar

\footnotetext{
${ }^{62}$ De acuerdo con KAHNEMAN (2012, p. 444), "el optimismo exagerado protege a los individuos y organizaciones de los efector paralizantes de la aversión a la pérdida; la aversión a la pérdida los protege de las temeridades del optimismo derivado del exceso de confianza".

${ }^{63}$ ARIELY (2011, p. 159 y 160). No obstante, como apunta el citado autor (p. 172) se trata de un aspecto sobre el que existen muchas incógnitas.

${ }^{64}$ Sobre el mantenimiento del statu quo o inercia ver infra.

${ }^{65}$ Aunque también es cierto que, si la conducta empresarial no se corrigiera en el momento de la contratación, al menos, durante los primeros compases de implantación de esta medida, es posible que se incrementaran los "costes de gestión", por el aumento de la litigiosidad.
} 
una reclamación judicial, asumiendo los costes que ello conlleva (manteniendo, por consiguiente, el statu quo - no accionando). El "optimismo no realista" podría también inducirles a pensar que si no accionan tendrán posibilidades de ser contratados de nuevo. En caso de sucesión de contratos temporales, la misma falta de información sobre la licitud de la causa y el temor a no ser contratados de nuevo (aversión a las pérdidas) también podrían estar detrás de la inacción. En cambio, la posibilidad de devengar salarios de tramitación en estos casos (como se ha sugerido), podría hacer más plausible la "expectativa de derecho" y, con ello, "hacer nacer" el efecto dotación. La consecuencia es que la aversión a las pérdidas llevaría a los trabajadores a asumir un comportamiento arriesgado (accionando judicialmente) con tal de no perder (en este caso, existe una posibilidad de cobrar la indemnización por despido improcedente $y$, según la propuesta que se sugiere, los salarios de tramitación).

\subsection{Disponibilidad}

Si los trabajadores son poco proclives a accionar judicialmente ante la sospecha de un contrato temporal ilícito, o bien, existe una probabilidad muy baja de ser sancionado administrativamente (porque el número de inspecciones tradicionalmente no es elevado), el comportamiento empresarial (“arriesgado") puede darse en un número de ocasiones muy superior (como ha estado sucediendo durante décadas). Lo que, dicho sea de paso, precipita una espiral negativa que se retroalimenta, pues, la ausencia de sanción contribuye a extender la convicción de que el incumplimiento es generalizado entre los ciudadanos y, por consiguiente, que los poderes públicos son tolerantes con él. Lo que lo convierte en un poderoso factor acelerador de su extensión (a través de la conformidad - como se apuntará en el epígrafe que sigue).

$\mathrm{Y}$, en este ámbito (y muy relacionado con el optimismo no realista recién descrito), lo que se conoce como heurístico de la disponibilidad puede tener un notable impacto. Como exponen KHANEMAN y TVERSKY (1974, p. 554 y 555), "la gente estima la frecuencia de una clase, o la probabilidad de un evento, por la facilidad con que ejemplos o sucesos acuden a su mente" "66. Y añaden, "la disponibilidad es un recurso útil para estimar la frecuencia o la probabilidad porque los ejemplos de grandes clases suelen recordarse mejor y más rápidamente que los ejemplos de clases menos frecuentes. Sin embargo, la disponibilidad resulta afectada por factores distintos de la

\footnotetext{
${ }^{66}$ Como apunta SUNSTEIN (2017, p. 32), el "Sistema 1" no maneja bien la probabilidad. De modo que "si un suceso está cognitivamente disponible, la gente tiende a sobreestimar el riesgo; si no lo está, puede subestimarlo". El "sesgo a la disponibilidad puede conducir a errores importantes respecto a la probabilidad de los malos resultados al adoptar la forma de un miedo excesivo o de una complacencia injustificada".
} 
frecuencia y la probabilidad. La consecuencia es que la confianza en la disponibilidad genera sesgos predecibles".

Es decir (LEWIS, 2018, p. 201), “cuanto más fácil se trae a la mente una situación cuanto más disponible esté -, más probable es que lo hagamos. Cualquier hecho o incidente que se especialmente vívido, reciente o común - o cualquier cosa que preocupe a una persona - tiene más probabilidades de ser recordado con facilidad, y se le dará una importancia desproporcionada en un juicio". Por ejemplo (siguiendo con el último autor citado), si se va conduciendo por la carretera y se pasa por un lugar en el que se ha producido un accidente en el pasado, tendemos a reducir la velocidad porque nuestra sensación de la probabilidad a verse envueltos en un accidente ha cambiado. $\mathrm{O}$ bien, la visualización de una película sobre el peligro de una guerra nuclear, hace que nos preocupemos más por ello $\mathrm{y}$, de hecho, sentimos que es más probable que ocurra. Así, "la misma volatilidad de los cálculos de probabilidades que llevan a cabo las personas - el hecho de que su sensación de probabilidad puede cambiar después de dos horas en un cine - nos dice algo sobre la fiabilidad del mecanismo que juzga estas probabilidades".

O, dicho de otro modo, siguiendo a SUNSTEIN (2006, p. 15), las personas en vez de "investigar la realidad se preguntan: ¿Puedo pensar en un ejemplo?”. Así, "si un incidente está rápidamente disponible en la mente pero es estadísticamente infrecuente, la gente va a sobreestimar el riesgo; si no vienen ejemplos a la mente pero el riesgo estadístico es alto, la heurística puede dar a la gente una sensación injustificada de seguridad"67. Por ejemplo, "la adquisición de seguros contra desastres naturales está en gran medida relacionada con experiencias recientes" (p. 64).

De hecho, la accesibilidad y visibilidad están muy relacionadas con la disponibilidad (SUNSTEIN y THALER, 2009, p. 41 y 42) ${ }^{68}$. Es decir, la experimentación personal de un determinado acontecimiento (o riesgo) influye en nuestra percepción sobre la probabilidad de su acaecimiento (más que si, por ejemplo, hemos leído al respecto). Y algo parecido sucede si son fáciles de imaginar (respecto a otras menos vívidas), o bien, se refieren a acontecimientos recientes (respecto a otros más lejanos en el tiempo). Y lo verdaderamente relevante es que el heurístico de la disponibilidad (y las valoraciones sesgadas de los riesgos que provoca) contribuye a explicar muchas conductas relacionadas con las contingencias que nos acechan y sobre todo nuestras decisiones a tomar precauciones. Especialmente porque (SUNSTEIN, 2006, p. 64 y 65) "la disponibilidad puede adormecer hasta la complacencia, puede volver invisibles ciertos

\footnotetext{
${ }^{67}$ Fenómeno que puede verse amplificado, como se ha apuntado supra en casos emocionalmente intensos, generando el "descuido de probabilidad".

${ }^{68}$ En estos casos, el sistema automático ("Sistema 1") es muy consciente del riesgo.
} 
riesgos a los que no se accede con facilidad, y se cumple eso de que ojos que no ven corazón que no siente".

En estos casos, una de las posibles medidas que a priori contribuirían a contrarrestar los efectos de la heurística de la disponibilidad en los empresarios sería, al igual que con nuestros problemas de autocontrol, que las instituciones incrementaran la información. Especialmente porque incidiría en los juicios acerca de los "beneficios" o ventajas que los empresarios asocian al uso de la contratación temporal ilícita. El objetivo es superar los problemas provocados por las limitaciones cognitivas, derivadas de la disponibilidad, procurando que la gente tenga una idea plena, en lugar de limitada, de lo que está en juego, sacándola de la inercia de la indiferencia (SUNSTEIN, 2006, p. 155). A su vez, si se acepta (SUNSTEIN y THALER, 2009, p. 113) que proporcionar "feedback" ayuda a los humanos a mejorar su rendimiento, el hecho de que el sistema legal no permita saber anticipadamente si se está actuando bien o mal (no facilita ninguna advertencia previa), salvo que concurra una eventualidad (intervención de la ITSS o inicio de una acción judicial - y, entonces, ya es demasiado tarde), puede dificultar la corrección de las conductas indeseadas ${ }^{69}$.

\subsection{Conformidad}

Es posible que, como se ha avanzado en el apartado anterior, el comportamiento ilícito también se vea fortalecido porque, tal y como exponen THALER y SUNSTEIN (2009, p. 73), las personas (los humanos), en tanto que forman parte de un "grupo" (Homo socialis $)^{70}$, se ven influidas fácilmente por otras. Y esto es así porque buscamos la conformidad (en nuestro objeto de estudio, la falsa percepción de la existencia de un comportamiento ilícito generalizado y/o ciertas convicciones también erróneas - como, por ejemplo, que el ordenamiento jurídico admite el "contrato temporal de prueba"). Los grupos, a través de la interacción social, son claros instrumentos de cambio, pues, tienen un enorme poder de influencia sobre sus miembros ${ }^{71}$.

De hecho, siguiendo con los citados autores (p. 76 y 77), la incidencia de las influencias sociales en nuestro comportamiento es muy poderosa ${ }^{72}$. Nuestro juicio personal no sólo

\footnotetext{
${ }^{69}$ Como exponen los citados autores (p. 96), en el lanzamiento de pelotas de golf es difícil calcular la distancia si no puede verse dónde caen, "puede estar todo el día practicando sin mejorar".

${ }^{70}$ Ver extensamente al respecto, OVEJERO BERNAL (2015), p. 89 y ss.

${ }^{71}$ OVEJERO BERNAL (2015), p. 97.

${ }^{72}$ Desde el punto de vista neurocientífico (LINDBERG, 2009, p. 69 a 71), las denominadas "neuronas espejo", son capaces de vencer al pensamiento racional y son las encargadas de repetir en la mente todas las acciones que observamos o leemos, ayudándonos, no sólo a imitar a otras personas, sino también son las encargadas de la empatía (ayudándonos a sintonizar con los sentimientos y reacciones de otras personas).
} 
puede verse fuertemente condicionado por el del grupo al que pertenecemos, internalizándolo por completo (aunque en privado se mantenga una postura opuesta), sino que, incluso, cambiando de grupo, somos proclives a adaptarnos a su juicio, aunque sea distinto al del anterior. Esta repercusión puede trascender "generaciones", sin que la renovación integral de los miembros del grupo afecte al mantenimiento del juicio inicial que se haya establecido en el grupo. En definitiva, los experimentos han evidenciado que con el tiempo puede afianzarse una "tradición", erigiéndose poderosas resistencias para redirigir estas inercias (como se apuntará posteriormente). Y que, en el ámbito del objeto de este ensayo, probablemente pueda identificarse con la existencia de una (consolidada) "cultura de la temporalidad".

La particularidad es que esta "inercia" es el resultado de lo que en la psicología social se conoce como "efecto congelación" o de adherencia a una decisión ya tomada, provocando una "escalada de compromiso", esto es, el apego a mantener ciertas decisiones, ideas o creencias, incluso, aunque sean erróneas ${ }^{73}$.

Lo que, a su vez, pone de manifiesto que, en ocasiones, los grupos son presa del "conservadurismo colectivo", esto es, la tendencia de los grupos a "aferrarse a las pautas establecidas aún después de que surjan nuevas necesidades. Una vez que una práctica (...) se afianza, es muy probable que se perpetúe, incluso si no tiene una base especial" 74 .

Y esto puede suceder, aunque esta "tradición" suponga una violación de la Ley. En efecto, algunas personas (siguiendo de nuevo a THALER y SUNSTEIN, 2009, p. 85 y 86) tienden a incumplir los mandatos legales por la percepción equivocada de que el porcentaje de ciudadanos que la cumplen es bastante bajo (lo que les lleva a sugerir que

${ }^{73}$ OVEJERO BERNAL (2015), p. 223 a 225. Lo que, como se ha expuesto anteriormente, tendría relación con el efecto dotación y la aversión a las pérdidas aplicados a las ideas o convicciones personales (y la dificultad de renunciar a ellas). En efecto, nuestra resistencia a aceptar otros planteamientos también puede estar relacionada con lo que se conoce como "la falacia de los costes hundidos". En efecto (THALER, 2016, p. 109 y ss.), la teoría de la elección racional sugiere que una vez efectuado un gasto y el dinero no se va a recuperar, éste es un "coste hundido" y, por consiguiente, nuestras decisiones deben ignorar totalmente estos costes. Sin embargo, a las personas nos cuesta mucho aceptar esta máxima y no tenerlos en cuenta en nuestras decisiones, de ahí que se hable de la "falacia de los costes hundidos". Y es posible que nuestra tendencia a aferrarnos a nuestras ideas sea una consecuencia de que prestamos excesiva atención a los costes hundidos (THALER, 2016, p. 373). En definitiva, perseveramos porque tenemos necesidad de una "autodefinición postiva", porque queremos "percibirnos a nosotros mismos como coherentes". OVEJERO BERNAL (2015), p. 225.

${ }^{74}$ El efecto del "falso consenso" (esto es -THALER, 2016, p. 391 -, que la gente "tiende a pesar de que todos los demás comparten sus preferencias"), es un aspecto de la psicología de la toma de decisiones que también, en hipótesis, podría tener una afectación en este ámbito. Ver al respecto también OVEJERO BERNAL (2015), p. 87. 
las "conductas deseables o no deseables pueden fomentarse atrayendo la atención pública hacia lo que hacen los demás" ${ }^{75}$ ).

En este sentido, la experiencia con respecto a las cartas enviadas por el Ministerio de Trabajo y Seguridad Social en verano de 2018 a los empresarios y la consiguiente conversión masiva de contratos temporales en indefinidos es una muestra clara de la efectividad (y potencial) de medidas de esta naturaleza.

En todo caso, tampoco puede obviarse que, el hecho de que en los medios de comunicación centren primordialmente su atención en los casos de incumplimiento de la ley (y no en los que se ajustan a la misma), puede alimentar poderosamente esta convicción (lo que, quizás, sugiera la necesidad de replantear las políticas de comunicación de las principales instituciones públicas que se ocupan de la "gestión" de estas cuestiones).

\subsection{Ansarinos, impronta, anclas e inercias}

Sin embargo, hay otro factor que, en hipótesis, quizás, también podría estar contribuyendo poderosamente a mantener esta pauta de comportamiento empresarial o, incluso, contribuir a alimentarla. Se trata de la impronta.

Siguiendo la exposición de ARIELY (2008, p. 43 y ss.), el naturalista K. LORENZ descubrió que los ansarinos, al salir del huevo, se apegan al primer objeto en movimiento que se encuentran (normalmente su madre); y, además, una vez tomada esa decisión inicial se atienen a la misma a lo largo del tiempo (de tal forma que si, en primer lugar, ven a una persona, le siguen fielmente a todas partes).

En el marco de la psicología conductual, la impronta no deja de ser una derivada de lo que se conoce como "asociación de ideas" (o mecanismo de asociación) ${ }^{76}$. A partir de

\footnotetext{
${ }^{75}$ Más ejemplos de esta naturaleza en SUNSTEIN (2014), p. 79.

${ }^{76} \mathrm{O}$, como manifestación del mismo, lo que se conoce como "priming" o "primado" (KHANEMAN, 2012, p. 74 y 75 y 164 a 166). Éste se refiere al descubrimiento hecho por los psicólogos de que "la audición de una palabra produce cambios inmediatos y mesurables en la fácil manera en que muchas palabras relacionadas pueden ser evocadas. Si recientemente hemos leído u oído la palabra COMER, estaremos temporalmente más dispuestos a completar el fragmento de la palabra JA_ÓN como JAMÓN que como JABÓN". Lo relevante del priming es que "no se limita a conceptos y palabras", sino que "nuestras acciones y emociones pueden ser primadas por acontecimientos de los que no somos conscientes" (como andar más lento si antes nos han pedido que formáramos frases con palabras asociadas con la ancianidad). No obstante (siguiendo a HAMMOND, 2016, p. 206 a 210), ciertas experimentaciones sobre los efectos del priming no son concluyentes, existiendo cierta controversia científica al respecto.
} 
este caso sobre los ansarinos, ARIELY (2008, p. 45) se pregunta si nuestras primeras impresiones y decisiones producen también una impronta y, en tal caso, qué papel juegan en nuestras vidas. Llevando esta reflexión a la compra de un producto y al precio asociado, se cuestiona si este precio inicial (que en la psicología conductual se denomina "ancla",77) tiene un efecto a largo plazo en nuestra predisposición a pagar por el producto en lo sucesivo. Y, tras la exposición de diversos experimentos, concluye que "nuestras primeras decisiones tienen eco en la larga secuencia de decisiones posteriores" (p. 56). De modo que las anclas que "han ejercido una influencia permanecen con nosotros hasta mucho después que la propia decisión inicial” (p. 56).

Llegados a este estadio, y tratando de proyectar esta reflexión al mercado de trabajo y, en concreto, al predominante uso de contratos temporales ilícitos, ¿podemos identificar un "ancla" en la legislación laboral que dé lugar a una impronta?

En un apartado anterior, se ha expuesto los efectos de las influencias sociales en nuestros juicios y el efecto de la "conformidad" y el "conservadurismo colectivo". No obstante, la política de empleo basada en la contratación temporal sometida simplemente a término a partir de 1977 (y hasta 1997) y, sobre todo, la inexistencia de indemnización por cumplimiento del término hasta 2001, ¿podría estar teniendo un efecto a largo plazo en la predisposición a seleccionar esta modalidad de contratación al margen de la concurrencia de las causas de temporalidad?

En relación a esta cuestión y como punto de partida, podría entenderse que, el hecho de que durante 20 años el fomento del empleo se potenciara a través del contrato temporal acausal (y sin coste al cumplirse el término), podría haber creado lo que (siguiendo con SUNSTEIN, 2012, 1, p. 13) se conoce como una recomendación implícita ("implicit endorsement"), de modo que se perciba la idea de que no conviene apartarse de la misma, salvo que se tengan poderosas razones. De hecho, "Muchas personas parecen pensar que la opción por defecto fue elegida por alguien sensato y por una buena razón. Especialmente si carecen de experiencia o no son expertos, pueden simplemente ceder a lo que se ha elegido para ellos".

\footnotetext{
77 Siguiendo a KHANEMAN y TVERSKY (1974, p. 558), "en muchas situaciones, la gente hace estimaciones a partir de un valor inicial ajustado para producir la respuesta final. El valor inicial, o punto de partida, puede haber sido sugerido por la formulación del problema, o bien puede ser el resultado de un cálculo parcial. En uno y otro caso, los ajustes son normalmente insuficientes. Esto significa que puntos de partida diferentes generan estimaciones diferentes que están sesgadas hacia los valores iniciales. A este fenómeno lo denominamos anclaje". De hecho, como exponen ARIELY y KREISLER (2018, p. 153 y 154), el anclaje puede ser arbitrario (a partir de una cifra aleatoria, como los últimos dígitos del número de la Seguridad Social). E, incluso, una vez tomada una primera decisión a partir de este primer anclaje aleatorio, se deja de pensar en el anclaje inicial, y se toma una segunda decisión en base a la primera (es lo que se conoce como "coherencia arbitraria").
} 
Y, en paralelo, siguiendo a ARIELY (2008, p. 69 y ss.) no puede obviarse el efecto que tiene en nuestro comportamiento el hecho de que algo sea "igratis!". Precisamente, atribuye esta atracción irrefrenable a nuestra aversión a las pérdidas anteriormente expuesta (pues, cuando algo es "igratis!", entendemos que no hay posibilidad alguna de pérdida). De hecho, el "efecto precio cero" es tan poderoso (casi "gravitacional") que puede llevarnos a tomar decisiones que son peores que otras alternativas a nuestro alcance mejores (por eso habla del "coste del coste cero"). Y, como apunta el citado autor junto con KREISLER (2018, p. 129), cuando algo es gratis, "cuesta mucho conseguir que, a partir de un determinado momento, se empiece a pagar por ello", pues, nos encariñamos y nos acostumbramos a ese precio. Especialmente porque, siguiendo con los mismos autores (2018, p. 155), "los anclajes iniciales son algunos de los fijadores de precios más importantes de nuestras vidas financieras, pues establecen un punto de referencia de la realidad, aquello que consideramos real y razonable durante mucho tiempo".

En efecto, adaptando el planteamiento de THALER (2016, p. 198), la política de fomento del empleo a través de la contratación temporal, podría haber fomentado un "sentimiento de posesión", de modo que cualquier deterioro de los términos iniciales, sea percibido como una pérdida, de modo que el statu quo se convierte en referencia ${ }^{78}$.

En general, reforzando esta idea recién apuntada y siguiendo a KAHNEMAN y TVERSKY (1984, p. 586 y ss.), "la aversión favorece la estabilidad frente al cambio", pues, si las pérdidas pesan más que las ganancias, las desventajas (entendidas como pérdidas) asociadas a estados alternativos al mantenimiento del statu quo, hacen que quien toma la decisión contraerá un sesgo que favorecerá mantenerse como estaba. Por consiguiente (SUNSTEIN y THALER, 2009, p. 51), "la aversión a la pérdida contribuye a producir inercia", pues, produce un "nudge ["empujón"] cognitivo que nos impulsa a no hacer cambios, incluso cuando éstos nos benefician mucho",79.

$\mathrm{Y}$, tratando de comprender mejor a la inercia, siguiendo a SUNSTEIN $(2012,1$, p. 11 y 12), para modificar una regla por defecto, las personas tienen que adoptar una elección activa rechazando esa regla. Lo que implica que deben centrarse en la misma y resolver una cuestión relevante (si mantenerla o no). Y añade: "Especialmente (pero no solo) si la pregunta es dificil o técnica, es tentador diferir la decisión o no tomarla en absoluto.

${ }^{78}$ En el fondo (THALER, 2016, p. 198), estas percepciones de justicia hacen que las condiciones habituales sean percibidas como un derecho adquirido y cualquier deterioro de tales términos es considerado como una pérdida. De modo que estas percepciones de justicia están relacionadas con lo que se conoce como "efecto dotación" anteriormente expuesto.

${ }^{79}$ Como apunta THALER (2016, p. 228), "la aversión a las pérdidas y el sesgo del statu quo suelen asociarse creando una fuerza poderosa que inhibe la propensión al cambio". 
En vista del poder de la inercia y la procrastinación, las personas simplemente pueden continuar con el status quo". De modo que, en estas situaciones (tal y como han evidenciado algunos experimentos neurológicos), las opciones por defecto acaban teniendo un poderoso efecto y tienden a prevalecer (porque la exclusión voluntaria es menos probable). Al descartar la opción por defecto (o lo que se venía haciendo desde hace mucho tiempo) fuerza a las personas a tener que construir o identificar preferencias alternativas y es posible que no tengan ninguna en concreto $\mathrm{y}$, por consiguiente, este esfuerzo sea todavía más duro o costoso. O, dicho de otro modo (ARIELY y KREISLER, 2018, p. 142), "no nos gusta nada vernos forzados a realizar elecciones difíciles, y desde luego no deseamos complicarnos la vida si no es necesario, por lo que tendemos a tomar la decisión más fácil y que nos resulte más familiar. Y a menudo esta decisión se ve influida por un punto de partida anclado en nuestra mente" ${ }^{\text {" }}$.

Efecto que podría verse especialmente potenciado en la medida que (ARIELY y KREISLER, 2018, p. 245), "nuestras experiencias pasadas también influyen en las expectativas sobre experiencias futuras", pues, una buena experiencia con un "producto" (en nuestro caso, un contrato temporal ilícito "no castigado"), puede inducirnos a sobrevalorarlo, "proyectando nuestra experiencia pasada hacia un posible consumo futuro" (y, ciertamente, nuestro "optimismo no realista" anteriormente descrito podría no ayudar a corregir esta percepción).

\section{Valoración final}

La temporalidad ilícita es un problema particularmente complejo en el que intervienen múltiples factores, algunos de ellos psicológicos.

Mientras el avance de la ciencia no permita determinar con nitidez los procesos neuronales que expliquen los factores que guían nuestras elecciones (de hecho, a eso se dedica lo que se conoce como "neuroeconomía" 81 ), es cierto que, hoy por hoy, la economía del comportamiento gravita a partir de un planteamiento básicamente introspectivo (al igual que la teoría de la elección racional). Dada la extrema complejidad del ser Humano y del proceso de toma de decisiones puede decirse que nos encontramos en una fase muy inicial del conocimiento de nosotros mismos. No

\footnotetext{
${ }^{80}$ Como exponen SUNSTEIN y THALER (2009, p. 117) “cuando nos hallamos ante un pequeño número de alternativas que conocemos bien, tendemos a examinar todas las características de todas las opciones $y$ después las sopesamos. Pero cuando las opciones son numerosas, tenemos que utilizar otras estrategias, y éstas nos pueden causar problemas", porque "se tiende a adoptar estrategias simplificadoras".

${ }^{81}$ De hecho, la neurociencia también está siendo aplicada, entre otros ámbitos, en el marketing y la política (LINDSTROM, 2009, p. 39 y ss.).
} 
obstante, es indiscutible que la experimentación ha permitido constatar la existencia de ciertas desviaciones sistemáticas y predecibles.

El contenido de este ensayo es una modesta descripción de esta rama de conocimiento en clara expansión. $\mathrm{Y}$ es importante advertir que, todas y cada una de las hipótesis descritas están fundamentadas en patrones de conducta extraídos de experimentaciones contrastadas (no son meras corazonadas o intuiciones). Si bien es cierto que ninguna de ellas (al menos que conozca) se han planteado específicamente en el ámbito objeto de este estudio, puede decirse (siguiendo con ARIELY, 2011, p. 10) que la lección que ha enseñado cada experimento no puede limitarse al reducido entorno del particular estudio en el que se inscribe, sino que hay elementos que permiten afirmar que estos ensayos son "ilustraciones de principios generales, que permiten entender mejor cómo pensamos y cómo tomamos decisiones en distintas situaciones de la vida". En definitiva, están permitiendo "comprobar de un modo directo y sin ambigüedades por qué los seres humanos somos como somos", proporcionándonos una "comprensión más profunda de las características y los matices de nuestros propios sesgos".

A la luz de lo expuesto, creo que es posible plantear, como mínimo en el plano teórico, la necesidad de trasladar esta matriz analítica al ámbito del mercado de trabajo y (entre otros muchos posibles), a la contratación temporal ilícita. Sin duda tienen un amplio recorrido por delante.

Las propuestas que se han planteado deben obviamente contrastarse y no descarto que, dada la complejidad del comportamiento humano en la toma de decisiones, algunas (o muchas) de las hipótesis que se formulan podrían ser enriquecidas, complementadas o, incluso, corregidas por aproximaciones analíticas más precisas o mejores. O, quizás, (tampoco descarto que) se haya pecado de una excesiva simplificación en algún estadio de la exposición.

En cualquier caso, el fraccionamiento de los costes asociados al despido objetivo (reduciendo la aversión a las pérdidas), el fomento del ahorro (limitando el sesgo hacia el presente), la posibilidad de exigir salarios de tramitación en caso de extinción de contratos temporales ilícitos, campañas de concienciación que, en aras a mitigar el optimismo no realista, contribuyan a hacer vívidos los riesgos vinculados a los comportamientos ilícitos (como las recientes cartas del Ministerio de Trabajo) son factores que, conjuntamente considerados, en hipótesis, podrían contribuir a mitigar algunos de los sesgos brevemente descritos en este ensayo. Y todo ello con el propósito de romper las patológicas y sólidamente asentadas inercias y así promover la contratación indefinida. 
Sin duda (y no sólo por lo anteriormente expuesto), debe ahondarse en el conocimiento de nuestro comportamiento en el entorno laboral. Especialmente porque los diversos enfoques descritos en este estudio ofrecen "otra" visión de estos fenómenos que no deberían ser menospreciada. En particular, porque, dado el potencial explicativo que atesoran, pueden convertirse en un oportuno complemento del análisis jurídico y, sin duda, en un poderoso prescriptor de la política legislativa a tener en cuenta (junto con otras variables y/o aproximaciones).

Especialmente porque, hasta la fecha, los instrumentos empleados para combatir la temporalidad ilícita han sido manifiestamente insuficientes y el precio que nuestra sociedad está asumiendo es manifiestamente intolerable.

\section{Bibliografía}

AKERLOF, G. A. (2002). «La macroeconomía conductual y la conducta macroeconómica». Revista Asturiana de Economía, núm. 25

AKERLOF, G. A. y SHILLER, R. J. (2016). La economía de la manipulación. Deusto, Bilbao.

AKERLOF, G. A. y SHILLER, R. J. (2009). Animal Spirits. Gestión 2000, Madrid.

ARIELY, D. (2011). Las ventajas del deseo. Ariel, Madrid.

ARIELY, D. (2008). Las trampas del deseo. Ariel, Madrid.

ARIELY, D. y KREISLER, J. (2018). Las trampas del dinero. Ariel, Madrid.

CABRILLO RODRÍGUEZ, F. y ALBERT LÓPEZ-IBOR, R. (2011), «El análisis económico del derecho en la encrucijada», Ekonomiaz, núm. 77.

CALABRESI, G. (1984), El coste de los accidentes. Ariel, Madrid

CALSAMIGliA, A. (1988), «Justicia, eficiencia y derecho», Revista del Centro de Estudios Constitucionales, núm. 1.

CALSAMIGLIA, A. (1987), «Eficiencia y derecho». DOXA, Cuadernos de Filosofía del Derecho, núm. 4.

CONTHE, M. (2007). La paradoja del bronce. Noema, Madrid. 
CORONA, J. F. (1993), «La racionalidad en el análisis económico», en Análisis Económico del Derecho y de la Política (Ed. Puy Fraga). Fundación Alfredo Bañas, Santiago de Compostela.

HAMMOND, C. (2016). La psicología del dinero, Penguin Random House, Barcelona.

HARARI, Y. N. (2015). Sapiens, Penguin Random House, Barcelona

KAHNEMAN, D. (2013). «Una perspectiva psicológica de la economía». Revista ius et veritas, núm. 46.

KAHNEMAN, D. (2012). Pensar rápido, pensar despacio. Penguin Random House, Barcelona.

KAHNEMAN, D. (2003). «Mapas de racionalidad limitada: psicología para una economía conductual». Revista Asturiana de Economía, núm. 28.

KAHNEMAN, D. y TVERSKY, A. (1984). «Elecciones valores y marcos». En Pensar rápido, pensar despacio. Debolsillo, Madrid.

LAKOFF, G. (2019). No pienses en un elefante. Península, Barcelona.

LEWIS, M. (2017). Deshaciendo errores. Debate, Barcelona.

LINDSTROM, M. (2009). Buyology. Gestión 2000, Barcelona.

OVEJERO BERNAL, A. (2015), Psicología Social, Biblioteca Nueva, Madrid.

PASTOR PRIETO, S. (1984), «Una introducción al análisis económico del derecho». Hacienda Pública Española, núm. 89.

QUINTANILLA, I. (2002). «Daniel Kahneman y la Psicología Económica». Revista de Psicología del Trabajo y de las Organizaciones, Volumen 18, núm. 1.

SANDEL, M. J. (2013). Lo que el dinero no puede comprar. Penguin Random House, Barcelona

SUNSTEIN, C. R. (2017), Paternalismo libertario: ¿por qué un empujoncito?, Herder Editorial. 
SUNSTEIN, C. R. (2014), (Más) Simple. Marcial Pons, Barcelona.

SUNSTEIN, C. R. (2012, 1), «Impersonal Default Rules vs. Active Choices vs. Personalized Default Rules: A Triptych», SSRN Electronic Library, Working Paper núm. 2171343 (2012), http://ssrn.com/abstract=2171343 (última consulta 2019/02/05).

SUNSTEIN, C. R. (2012, 2), «Análisis conductual del derecho», Themis-Revista de Derecho, núm. 62.

SUNSTEIN, C. R. (2009), Leyes de miedo. Katz, Buenos Aires.

SUNSTEIN, C. R. (2006), Riesgo y razón. Katz, Buenos Aires.

SUNSTEIN, C. R. y THALER, R. H. (2009). Un pequeño empujón. Taurus, Barcelona.

SUNSTEIN, C. R., JOLLS, C. y THALER, R. H. (1998), «A Behavioral Approach to Law and Economics». Stanford Law Review, 50(5). Disponible en: https://chicagounbound.uchicago.edu/cgi/viewcontent.cgi?article=12172\&context=jour nal_articles (última consulta: 11/02/2019).

TALEB, N. N. (2011). El cisne negro. Paidós, Barcelona.

THALER, R. H. (2016). Todo lo que he aprendido con la psicología económica. Deusto, Barcelona.

TIROLE, J. (2018). La economía del bien común. Penguin Random House, Barcelona.

TVERSKY, A. y KAHNEMAN, D. (1974). «El juicio bajo incertidumbre: heurísticas y sesgos». En Pensar rápido, pensar despacio. Penguin Random House, Barcelona.

ULLEN, T. S. (2015). «La importancia del derecho conductual». Revista de Teoría del Derecho de la Universidad de Palermo, núm. 1.

ULLEN, T.S. (1999). «Rational choice theory in law and economics». Disponible en https://reference.findlaw.com/lawandeconomics/0710-rational-choice-theory-in-lawand-economics.pdf (última consulta 11/02/2019). 